\title{
Liver fibrosis affects the targeting properties of drug delivery systems to macrophage subsets in vivo
}

\author{
Can Ergen*, 1,2, Patricia Niemietz*,2, Felix Heymann*,2,3, Maike Baues ${ }^{4}$, Felix \\ Gremse $^{4}$, Robert Pola ${ }^{5}$, Louis van Bloois ${ }^{6}$, Gert Storm ${ }^{6}$, Fabian Kiessling ${ }^{4}$, Christian \\ Trautwein $^{2}$, Tom Luedde ${ }^{2}$, Twan Lammers ${ }^{4,6,7}$, Frank Tacke ${ }^{2,3}$
}

${ }^{1}$ Department of Medicine I, University Hospital Hamburg-Eppendorf, Hamburg, Germany

${ }^{2}$ Department of Medicine III, University Hospital Aachen, Aachen, Germany

${ }^{3}$ Department of Hepatology and Gastroenterology, Charité University Medicine Berlin, Berlin, Germany

${ }^{4}$ Department of Experimental Molecular Imaging, University Clinic and Helmholtz Institute for Biomedical Engineering, RWTH Aachen University, Aachen, Germany ${ }^{5}$ Institute of Macromolecular Chemistry, Academy of Sciences of the Czech Republic, Prague, Czech Republic

${ }^{6}$ Department of Pharmaceutics, Utrecht Institute for Pharmaceutical Sciences, Utrecht University, Utrecht, The Netherlands

${ }^{7}$ Department of Targeted Therapeutics, MIRA Institute for Biomedical Technology and Technical Medicine, University of Twente, Enschede, The Netherlands

*these authors contributed equally to this work

Corresponding author: Frank Tacke, M.D., PhD (Email: frank.tacke@gmx.net) 


\begin{abstract}
Myeloid immune cells promote inflammation and fibrosis in chronic liver diseases. Drug delivery systems, such as polymers, liposomes and microbubbles, efficiently target myeloid cells in healthy liver, but their targeting properties in hepatic fibrosis remain elusive. We therefore studied the biodistribution of three intravenously injected carrier material, i.e. $10 \mathrm{~nm}$ poly( $N$-(2-hydroxypropyl)methacrylamide) polymers, 100 nm PEGylated liposomes and $2000 \mathrm{~nm}$ poly(butyl cyanoacrylate) microbubbles, in two fibrosis models in immunocompetent mice. While whole-body imaging confirmed preferential hepatic uptake even after induction of liver fibrosis, flow cytometry and immunofluorescence analysis revealed markedly decreased carrier uptake by liver macrophage subsets in fibrosis, particularly for microbubbles and polymers. Importantly, carrier uptake co-localized with immune infiltrates in fibrotic livers, corroborating the intrinsic ability of the carriers to target myeloid cells in areas of inflammation. Of the tested carrier systems liposomes had the highest uptake efficiency among hepatic myeloid cells, but the lowest specificity for cellular subsets. Hepatic fibrosis affected carrier uptake in liver and partially in spleen, but not in other tissues (blood, bone marrow, lung, kidney). In conclusion, while drug carrier systems target distinct myeloid cell populations in diseased and healthy livers, hepatic fibrosis profoundly affects their targeting efficiency, supporting the need to adapt nanomedicine-based approaches in chronic liver disease.
\end{abstract}

Abstract word count: 205 words

\title{
Keywords
}

Liver fibrosis; Targeted delivery; Nanomedicine; Macrophages; Polymers; Liposomes; Microbubbles 


\section{Introduction}

Liver fibrosis has become an increasing health-related issue [1]. One of the main reasons is the dramatic increase of non-alcoholic fatty liver disease, which has reached a worldwide prevalence of around 25\% [2]. Hepatic fibrosis, i.e. scarring of the liver, is considered the main driver of morbidity and mortality in non-alcoholic steatohepatitis and other chronic liver diseases [3]. In contrast to this increasing need, no specific therapy against the progression of liver fibrosis has been approved, but many compounds are currently under clinical investigation [4].

In the past decade, an increasing number of preclinical studies has investigated nanomedicine-based approaches in experimental models of liver fibrosis [5]. Nanomedicine formulations principally allow for drug targeting to specific cell types in the liver that drive the progression of fibrosis. In most of these approaches, four different cell types have been addressed as potential target populations (i.e., hepatic stellate cells, hepatocytes, liver sinusoidal endothelial cells, and myeloid cells), and targeting these various cell types by different strategies have demonstrated beneficial effects on experimental fibrosis [6-11]. For instance, PEGylated liposomes loaded with dexamethasone without specific targeting moieties showed a preferential uptake in liver macrophages, resulting in a reduction of fibrosis [6].

Among the different cells involved in hepatic fibrogenesis, myeloid cells are particularly attractive targets, because these cells efficiently take up various carrier systems without additional specific targeting molecules in healthy liver [12]. Myeloid cells consist mainly of Kupffer cells as well as monocyte-derived macrophages (MoMF) and show a high abundance in the liver (20-40 phagocytes per 100 hepatocytes) [13]. Kupffer cells, the resident macrophage population in the liver, are highly effective phagocytes clearing the blood from cellular debris, pathogens and foreign material [14]. This uptake leads to the induction of tolerogenic T cells under homeostatic conditions [15]. In liver diseases, MoMF infiltrate the liver, release proinflammatory mediators and promote the activation of collagen-producing myofibroblasts [16]. Due to their capability to transition between a pro- and antifibrotic phenotype, liver macrophages are a promising target for nano- and micrometersized drug delivery systems [14].

In this study, using two mouse models of liver fibrosis, we aim to provide insight into the biodistribution and targeting efficiency/specificity of three established drug delivery systems: poly( $N$-(2-hydroxypropyl)methacrylamide) (pHPMA) polymers 
(average size $\sim 10 \mathrm{~nm}$ ) [17], PEGylated liposomes (100 nm) [6] and poly(butyl cyanoacrylate)-based (PBCA) microbubbles $(2 \mu \mathrm{m})$ [18]. These carrier materials differ in various physicochemical properties, like size, surface charge and composition. Upon intravenous injection of carrier systems, these carriers can bind to proteins in blood and this may alter the properties of the carrier [19]. These protein corona can lead to masking of targeting molecules, increased interaction with scavenging molecules or immunogenicity of the carrier. The formation of the corona is mainly dependent on the surface charge and hydrophobicity of the carrier molecule. For cellular uptake, carriers can interact either with cells in the blood stream like blood leukocytes or Kupffer cells or cross the endothelium and interact with interstitial cells [20]. The mechanism of uptake of carrier molecules is dependent on the size, the surface charge and receptor interaction with the target cell [21]. The complex interaction of drug carriers leads to a differential uptake by distinct myeloid cells in homeostasis [12]. Due to various alterations in liver fibrosis, related to structural (e.g., extracellular matrix), vascular (e.g., leaky endothelial barrier and angiogenesis) or immunological changes (e.g., immune cell infiltration), we set out to examine whether this fundamental transformation affects the cellular biodistribution of typical drug delivery systems. In addition, we examined whether liver fibrosis affects targeting (to immune cell populations) in other organs, like spleen, kidney and lung [22-24]. To study the biodistribution and cell-specific targeting, we used multicolor flow cytometry to distinguish myeloid and lymphoid cells, fluorescence microscopy to study carrier localization in the diseased liver as well as micro-computed tomography - fluorescencemediated tomography ( $\mu \mathrm{CT}$-FMT) to relate these findings to whole-body biodistribution and organ uptake $[25,26]$. To allow for the integration of these techniques, we established two mouse models of liver fibrosis in immunocompetent and hairless SKH1-e mice. 


\section{Results and Discussion}

To investigate the effect of liver fibrosis on particle distribution in vivo, two different models of chronic liver injury were studied. The repetitive injection (2x /week for 6 weeks) of carbon tetrachloride $\left(\mathrm{CCl}_{4}\right)$ i.p. results in a typical periportal fibrosis, while the dietary challenge with a methionine and choline-deficient (MCD) diet for 8 weeks induces steatohepatitis with perisinusoidal fibrosis (Fig. 1). To test the biodistribution in fibrotic animals, we i.v. injected three clinically relevant nano- and microcarriers, namely pHPMA polymers (10 nm), PEGylated liposomes (100 nm) and PBCA-based microbubbles $(2 \mu \mathrm{m})$. All carrier materials were labeled with a near-infrared fluorophore for $\mu \mathrm{CT}$-FMT and by a standard fluorescent dye for flow cytometry and immunofluorescence, as previously established [12]. Optical imaging is greatly facilitated in fur-free mice, which prompted us to explore fibrosis development in SKH1-e mice. $\mu$ CT-FMT was performed 15 minutes, 1 hour, 4 hours and 24 hours after carrier injection. In the same mice, flow cytometry of single cell suspensions from liver, blood, spleen, bone marrow, kidney and lung were analyzed 24 hours after carrier material injection. Immunofluorescence microscopy was performed on $5 \mu \mathrm{m}$ thick cryosections, using an antibody against CD11b.

\section{Validation of fibrosis models in fur-free SKH1-e mice}

For both models of chronic liver damage, strain specific phenotype differences were described [27]. We used a six-week $\mathrm{CCl}_{4}$ treatment regimen with twice weekly i.p. injections so that bridging fibrosis should be apparent. For the MCD model, we used eight weeks of diet, which should lead to marked steatosis and fibrosis [28]. Both models are usually accompanied by pronounced immune cell infiltrates.

In both models, SKH1-e mice showed chronic liver disease. After treatment with $\mathrm{CCl}_{4}$, bridging fibrosis was visible by histology and Sirius red staining (Fig. 2). In addition, there was a prominent infiltration of $\mathrm{F} 4 / 80^{+}$macrophages showing a periportal distribution. After MCD diet, excessive steatosis and mild fibrosis were visible in histology and Sirius red staining (Fig. 2). F4/80 macrophages were visible in perisinusoidal and pericentral regions, and some macrophages contained lipid droplets. The net amount of hepatic fibrosis in fur-free SKH1-e mice as well as the other histological and biochemical features of liver injury were comparable to c57bl/6 mice, the standard model in experimental liver fibrosis [29]. 


\section{Drug carrier systems preferentially accumulate in the liver in homeostasis and fibrosis}

Optical imaging is a well-established method to monitor the carrier biodistribution in vivo [26, 30]. We imaged the carrier distribution using $\mu$ CT-FMT in SKH1-e mice [31] to assess the whole-body distribution of polymers, liposomes and microbubbles in control animals as well as in $\mathrm{CCl}_{4}$-induced fibrosis. Whole-body imaging in mice under MCD diet was not performed, because chlorophyll in the MCD-deficient food can lead to increases in background signal, and changing the food several days before imaging to chlorophyll-free food would lead to decreased inflammation [25, 32]. To compare the carrier biodistribution after MCD treatment with the other two treatment conditions (control and $\mathrm{CCl}_{4}$ ), we used ex vivo, post-mortem FMT of liver, spleen, kidney, heart, skin, and lung in all three models.

For kinetic studies of carrier biodistribution, we segmented the different organs based on $\mu \mathrm{CT}$ scans and determined carrier accumulation based on the in vivo FMT signal (Fig. 3A). Circulation times were assessed using the signal in the segmented cardiac region. The blood half-life was comparable to our previous study, that means no change was visible after the induction of fibrosis [12]. Thereby, we show that carrier clearance is not impaired after induction of fibrosis, which is in contrast to findings described for protein uptake with targeting moieties and pathogens [33, 34]. For all carriers and irrespective of the induction of liver fibrosis, the liver was the organ with the highest uptake of all three carriers. The uptake of liver accounted for up to $30-40 \%$ of the injected dose after 24 hours. Neither the amount of carrier uptake in the liver nor the kinetics of carrier material uptake changed after induction of liver fibrosis (Fig. 3B, C). Among all segmented extrahepatic organs, the spleen was the only one that showed a significant increase in carrier uptake for liposomes and polymers (Fig. 3B). However, at the same time, splenomegaly was visible after $\mathrm{CCl}_{4}$ treatment. Splenomegaly is a well-known feature of human liver cirrhosis related to portal hypertension and has been shown to develop as well in mice upon chronic liver damage [35]. Therefore, we corrected the intensity for the respective spleen volume and found no differences in the volume-corrected splenic carrier uptake between control and $\mathrm{CCl}_{4}$-treated animals for all carriers (Fig. 3B). We thereby show that the phagocytic activity of the spleen is directly proportional to the mean spleen size, which matches results in humans [36] and matches the observation that splenomegaly leads to higher phagocytic activity of splenic macrophages [37]. 
Comparing the two models of liver fibrosis on a whole-body level, the liver was the prime target of all three prototypic drug carrier systems (Fig. 3C). In addition, using ex vivo FMT, we observed a decrease in intensity after liposome injection in the lung and kidney in both fibrosis models, which was not detected by the in vivo $\mu \mathrm{CT}$-FMT assessment (Suppl. Fig. 1). This differing result might be attributed to the fact that in vivo the organ uptake and the relative blood volume are not distinguishable. In contrast, after sacrificing the mice a cardiac puncture was performed leading to almost no blood in the organs. Therefore, ex vivo measured fluorescence might better reflect the organ uptake especially in organs with low carrier uptake, because the relative proportion of the carrier in blood is higher in these organs. Collectively, on a whole-body level, only minor differences were observed between control mice and mice subjected to experimental fibrosis, with a clear accumulation of all three carrier systems in the liver.

\section{Liver macrophage subsets display a reduced uptake of microbubbles and polymers in fibrosis}

We observed an increased number of macrophages after induction of liver fibrosis (Fig. 2), but only minor differences in carrier uptake in fibrotic livers compared to healthy livers (Fig. 3). Therefore, we next assessed which cellular subpopulations take up the different carrier materials in homeostasis and liver fibrosis. We therefore characterized carrier uptake by distinct hepatic cell populations, discriminating granulocytes

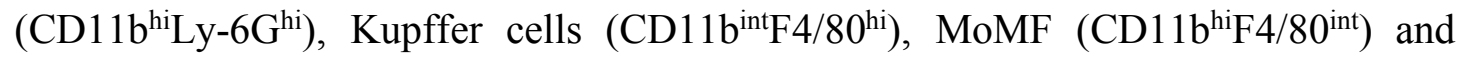
monocytes $\left(\mathrm{CD} 11 \mathrm{~b}^{\mathrm{hi}} \mathrm{F} 4 / 80^{\text {lo }}\right)$ as well as endothelial cells $\left(\mathrm{CD} 45^{\mathrm{lo}} \mathrm{CD} 31^{\text {hi }}\right)$ (Fig. 4A).

By flow cytometry, an increase in MoMF was detectable, while the number of Kupffer cells decreased after the induction of liver fibrosis (data not shown), in line with prior observations [28]. Assessing the carrier-specific fluorescent intensity of the different cellular populations, e.g. MoMF (Fig. 4B), allowed a granular analysis of the targeting efficiency for the different cell types and carrier systems. This analysis revealed a decreased uptake of polymers and microbubbles by almost all myeloid cells of the liver (Fig. 4C). This decrease was significant for all cell types in the MCD model, whereas we noted in the $\mathrm{CCl}_{4}$ model no significant decrease for microbubbles in granulocytes and for polymers in Kupffer cells (Fig. 4C). The decrease was more pronounced in the MCD model than in the $\mathrm{CCl}_{4}$ fibrosis model for all myeloid cell populations. For polymers, the most pronounced decrease in carrier uptake was visible in hepatic granulocytes and monocytes, where almost no uptake was visible in mice with 
steatohepatitis. In contrast, we detected no significant decrease in carrier uptake by endothelial cells, but a very low uptake of microbubbles by endothelial cells in vivo (Fig, 4C).

In contrast to microbubbles and polymers, liposomes had an overall higher targeting efficiency for endothelial and myeloid cells, which remained high even in fibrotic livers. After injection of liposomes, the only significant decrease in carrier-positive cells was seen for $\mathrm{MoMF}_{\mathrm{Mn}} \mathrm{CCl}_{4}$ injected mice. In all cell types, there was a high uptake of liposomes detectable with around $60 \%$ carrier positive cells in healthy liver and after induction of liver fibrosis.

Thus, liver fibrosis profoundly changes the myeloid compartment in the liver, with decreasing numbers of Kupffer cells and increasing numbers of MoMF, which are accompanied by substantially lower targeting efficacy of polymers and microbubbles. For liposomes, we did not detect a decrease in the number of carrier-positive myeloid cells after induction of liver fibrosis, and liposomal targeting efficiency was high with a low specificity for the various cell populations.

\section{Analysis of carrier biodistribution in extrahepatic organs and in lymphoid cells}

We found a decrease in the amount of carrier-positive granulocytes in fibrotic livers. Because neutrophils have a short half-life even after infiltration into diseased organs, we asked whether this decrease is paralleled by a decrease in carrier uptake of neutrophils in blood. We analyzed carrier uptake by myeloid cells in blood looking at granulocytes (CD11b ${ }^{\text {hi }}$ Ly-6G ${ }^{\text {hi }}$ ) as well as Ly-6C ${ }^{\text {hi }}$ and Ly-6C ${ }^{\text {lo }}$ monocytes (CD1 1b ${ }^{+}$Ly$\left.6 \mathrm{G}^{\text {neg }} \mathrm{Ly}-6 \mathrm{C}^{+/}\right)$(Fig. 5). Looking at the various carriers, no significant differences were visible by means of administrating the respective carrier after induction of liver fibrosis. Liposomes were particularly efficient in labeling circulating myeloid cells. We found the highest carrier uptake by Ly-6C ${ }^{\text {lo }}$ monocytes, which are considered to be more active phagocytes compared to Ly-6 $\mathrm{C}^{\text {hi }}$ monocytes [38].

In whole-body imaging (Fig. 3), we could show an overall increase by splenic uptake of all three carriers, which could be attributed to the increased spleen size after induction of the fibrosis, similar to human splenomegaly in patients with cirrhosis [36]. In order to assess whether this overall increased carrier uptake in spleen is accompanied by a shift in the cellular biodistribution, we analyzed myeloid cells in the spleen looking at granulocytes $\left(\mathrm{CD} 11 \mathrm{~b}^{\mathrm{hi}} \mathrm{Ly}-6 \mathrm{G}^{\mathrm{hi}}\right)$, monocytes $\left(\mathrm{CD} 11 \mathrm{~b}^{+} \mathrm{Ly}-6 \mathrm{G}^{\mathrm{lo}} \mathrm{F} 4 / 80^{\mathrm{lo}}\right)$ and red pulp macrophages $\left(\mathrm{CD} 11 \mathrm{~b}^{\mathrm{lo}} \mathrm{Ly}-6 \mathrm{G}^{\mathrm{lo}} \mathrm{F} 4 / 80^{\mathrm{hi}}\right)$ (Fig. 5). These cells account for the majority of 
phagocytes in the spleen, while marginal zone macrophages and metallophilic macrophages represent additional specialized myeloid cells in the spleen [39, 40]. In contrast to all other analyzed cell populations, where a decrease or stable uptake of the three carriers was visible after induction of fibrosis, there was an increase in microbubble positive splenic monocytes detectable in the MCD model but not in the $\mathrm{CCl}_{4}$ model. In addition, this tendency (not significant) was also visible after MCD diet in the polymer group. This observation fits well to the systemic inflammation observed in steatohepatitis, where liver fibrosis is typically linked to inflammatory responses in other compartments including adipose tissue inflammation, blood vessels (atherosclerosis), intestine and spleen [41]. For red pulp macrophages, there was a tendency towards decreased uptake after induction of fibrosis (significant only for polymer uptake by red pulp macrophages after MCD treatment and liposome uptake by granulocytes). Both of these cell types have divergent functions. Red pulp macrophages are embryonically derived macrophages that phagocytose senescent erythrocytes and regulate iron homeostasis [42], whereas splenic monocytes form a reservoir of mature monocytes that can exit the spleen in case of injury somewhere else in the body [43], possibly contributing to the progression of liver fibrosis [35].

In the kidney, we distinguished between conventional and resident dendritic cells $\left(\mathrm{CD} 11 \mathrm{~b}^{\mathrm{lo} / \mathrm{hi}} \mathrm{CD} 11 \mathrm{c}^{\mathrm{hi}} \mathrm{Ly}-6 \mathrm{G}^{\mathrm{lo}}\right)$, granulocytes $\left(\mathrm{CD} 11 \mathrm{~b}^{\mathrm{hi}} \mathrm{Ly}-6 \mathrm{G}^{\mathrm{hi}}\right)$ and endothelial cells $\left(\mathrm{CD} 31^{\text {hi }} \mathrm{CD} 45^{\text {lo }}\right)$. Uptake was very low for microbubbles in the kidney compared to all other organs. In agreement with our previous study on healthy animals, the relative uptake of liposomes was high in renal myeloid cells [12]. Comparing control to fibrotic mice, the only significant change was visible in microbubble uptake after MCD treatment for resident dendritic cells (1.8\% vs. 5.4\%). These cells are phagocytically active, express F4/80 and have features of macrophages and dendritic cells [44].

Furthermore, we analyzed the carrier uptake in bone marrow and lung (Suppl. Fig. 2). In bone marrow, we distinguished between granulocytes $\left(\mathrm{CD} 11 \mathrm{~b}^{\mathrm{hi}} \mathrm{Ly}-6 \mathrm{G}^{\mathrm{hi}}\right)$, Ly6 $\mathrm{C}^{\mathrm{hi}}$ and Ly6C ${ }^{\text {lo }}$ monocytes $\left(\mathrm{CD} 11 \mathrm{~b}^{+} \mathrm{Ly}-6 \mathrm{G}^{\mathrm{lo}} \mathrm{Ly}-6 \mathrm{C}^{\mathrm{h} / \mathrm{lo}}\right)$, dendritic cells $\left(\mathrm{CD} 11 \mathrm{c}^{\text {hi }} \mathrm{MHC}-\mathrm{II}^{+}\right)$and macrophages $\left(\mathrm{CD} 11 \mathrm{~b}^{\mathrm{int}} \mathrm{Ly}-6 \mathrm{G}^{\mathrm{lo}} \mathrm{F} 4 / 80^{\mathrm{hi}}\right)$. While all bone marrow myeloid cells were targeted by liposomes, only macrophages were targeted by microbubbles and polymers in the bone marrow. After the induction of fibrosis, no significant differences were visible for the analyzed cells in bone marrow (Suppl. Fig. 2). In the lung, there are two major phagocyte populations present, alveolar macrophages (defined as $\mathrm{CD} 11 \mathrm{c}^{\text {hiF}} \mathrm{F} / 80^{+} \mathrm{CD} 11 \mathrm{~b}^{\text {lo }}$ cells with a high autofluorescence) and interstitial 
macrophages as well as monocytes (defined as CD11 $\mathrm{c}^{\mathrm{lo}} \mathrm{CD} 11 \mathrm{~b}^{+} \mathrm{F} 4 / 80^{+/-}$)[45]. Specific gating strategies allowed a clear separation of the different myeloid cell populations, including monocytes $\left(\mathrm{CD} 11 \mathrm{~b}^{+} \mathrm{F} 4 / 80^{-} \mathrm{Ly}-6 \mathrm{G}^{\mathrm{lo}}\right)$ passaging the lung. We found no significant differences in carrier uptake after induction of liver fibrosis. A high uptake was visible in Ly-6C monocytes for all three carriers (Suppl. Fig. 2).

In parallel to the myeloid cell populations, we also analyzed the major lymphoid cells ( $\mathrm{T}$ and B cells) in all organs (Suppl. Fig. 3). In the liver, lymphoid cells are practically not targeted by polymer or microbubbles at all, while liposomes label some conventional $\mathrm{T}$ and $\mathrm{B}$ lymphocytes, yet at much lower numbers compared to myeloid cells (Suppl. Fig. 3, compare to Fig.4). A higher number of carrier positive cells was only visible in B cells of bone marrow, spleen and blood after injection of liposomes. In the comparison of carrier-material uptake between control mice and after induction of fibrosis, there was no statistical difference detectable in all lymphoid cells studied.

\section{Liposome uptake per cell is significantly reduced in liver macrophage populations in hepatic fibrosis}

Liposomes were very broadly detected after intravenous injection in almost all myeloid cell populations and in all examined organs in control and fibrotic mice. The analysis of fluorescence intensity by flow cytometry allowed to quantify the amount of liposome uptake per cell (Fig. 6 and Suppl. Fig. 4). This analysis could not be reliably performed for microbubbles or polymers, due to their lower fluorescence intensity per cell and lower relative uptake, which leads to a mean fluorescence intensity (MFI) close to the background cellular autofluorescence [12]. We found a drastically decreased fluorescence intensity per cell in Kupffer cells and MoMF after induction of liver fibrosis, indicating an uptake of much fewer liposomes per cell in these two dominant hepatic macrophage subsets (Fig. 6).

On the contrary, liposomal uptake per cell was much less affected in the extrahepatic organs (Fig.6 and Suppl. Fig. 4). In the spleen, the uptake of liposome by red pulp macrophages decreased significantly after induction of liver fibrosis, while carrier uptake by monocytes increased. This is in parallel to past observations showing an increasing in the phagocytic activity of splenic CD68 positive cells in humans with liver fibrosis [37]. In kidney, blood, lung and bone marrow, minor differences were detected between control and fibrotic mice, not reaching statistical significance. 


\section{Prototypic drug carrier systems target myeloid cells in inflammatory infiltrates in fibrotic liver}

After determining the cellular biodistribution of the various carrier systems in different organs, we next assessed the localization of carrier-positive cells in liver tissue. Hepatic macrophages exert different function depending on their micromilieu. For instance, in fatty liver disease, the fat overload in hepatocytes leads to cell death of hepatocytes, which activates macrophages and leads to lipid-laden macrophages [41]. After initial induction of hepatocyte damage, F4/80 positive lipid-laden macrophages form small clusters and express pro-inflammatory and fibrogenic cytokines (TNF- $\alpha$ ), but also several anti-inflammatory mediators (Annexin A1, IL-10) [46]. During chronic $\mathrm{CCl}_{4}$ treatment, dense infiltrates of monocytes form in the periportal region and exhibit an angiogenic and fibrogenic phenotype. These cells activate hepatic stellate cells, promoting extracellular matrix protein deposition [16, 47]. In addition, macrophages are able to change their phenotype and produce metalloproteinases to actively resolve tissue fibrosis [16]. Reaching macrophages in these dense infiltrates might therefore be a promising strategy in the therapy of chronic liver disease.

We analyzed the uptake of carriers by myeloid cells using co-staining for the myeloid marker CD11b, which marks neutrophils, monocytes and MoMF, in fluorescence microscopy. Antibody staining requires the fixation with methanol or acetone, which partially dissolves the fluorophore for liposomes and leads to a broader fluorophore distribution compared to directly imaged liposomes (Suppl. Fig 5). As expected, increasing numbers of $\mathrm{CD}_{1} 1 \mathrm{~b}^{+}$cells were visible after induction of fibrosis using $\mathrm{CCl}_{4}$ injections or MCD diet (Fig. 7). After $\mathrm{CCl}_{4}$ treatment, we observed autofluorescent cells in periportal regions, highly indicative for necrotic hepatocytes. Around those areas, an increased number of $\mathrm{CD}_{1} 1 \mathrm{~b}^{+}$cells was visible, forming the expected periportal infiltrates. After MCD diet, autofluorescent cells staining positive for CD11b were visible, highly indicative of lipid-laden cells as a typical feature of steatohepatitis. After microbubble injection, we found some colocalization of $\mathrm{CD}_{1} 1 \mathrm{~b}^{+}$cells and microbubbles under steady state conditions (Fig. 7). In accordance with prior reports [12], microbubbles showed a distribution that spares the pericentral region, which can be explained by the fast and efficient sequestration of this carrier by Kupffer cells in the sinusoids. In $\mathrm{CCl}_{4}$-induced hepatic fibrosis, there was a pronounced periportal pattern visible showing increased carrier uptake in the regions of tissue damage (autofluorescent areas). After treatment with MCD diet, the preferential uptake in 
periportal regions was less visible, and some microbubbles were visible close to the pericentral lipid-laden cells. However, there was still a tendency towards a periportal distribution.

After liposome injection, there was a broad distribution of carrier-positive cells visible under steady state (Suppl. Fig. 5) with a higher number of liposome-positive cells around larger vessels. In $\mathrm{CCl}_{4}$-induced hepatic fibrosis, almost the entire signal was visible in periportal regions (Fig. 7). The weaker signal in pericentral regions was nearly gone after induction of fibrosis. The fluorescent pattern resembles the distribution of immune cell infiltrates. In contrast, in the MCD model, there was a clear tendency towards a pericentral distribution of liposome-positive cells, and liposomes were found inside the lipid-laden macrophages showing that these cells are still phagocytic and actively take up liposomes (Fig. 7).

After polymer injection, there was a broad distribution of carrier positive cells in healthy liver. Colocalization with $\mathrm{CD}_{11} \mathrm{~b}^{+}$cells were rarely seen. $\mathrm{In} \mathrm{CCl}_{4}$-induced hepatic fibrosis, there was an increasing colocalization with anti-CD11b (Fig. 7). In addition, almost no signal was visible in pericentral regions. After induction of steatohepatitis by MCD diet, almost no signal was visible in periportal regions and most of the signal is visible in close neighborhood to the lipid-laden cells (Fig. 7). These data demonstrate that polymers colocalize with areas of tissue damage, indicating that drug delivery to these regions might be possible by using this carrier.

Taken together, the spatial biodistribution of all carriers was clearly influenced by the fibrosis model. The distribution of the carriers resembles to a large extent the distribution of immune infiltrates in the respective disease model. For microbubbles, this effect was found to be the least pronounced, while this observation was the most pronounced for liposomes. This differential accumulation of the carrier systems is in good agreement with the flow cytometry data, supporting that microbubbles are preferentially taken up by professional phagocytes, polymers are also taken up by professional phagocytes but less efficiently leading to a higher specificity of targeting inflamed regions, and liposomes display a much broader distribution and lower cell subset specificity.

These pronounced differences in carrier biodistribution after induction of liver fibrosis might be attributed to various factors. Even though administration route and carrier composition were the same after induction of fibrosis, described changes in albumin for the $\mathrm{CCl}_{4}$ model [48] and in parallel perhaps other proteins synthetized by the liver, 
as e.g. complement, might change the opsonization of the carrier before it enters the hepatic circulation and thereby influence the cellular biodistribution. Liver sinusoidal endothelial cells lose fenestrae upon induction of liver fibrosis [49], therefore enhanced permeability and retention is not expected to increase carrier uptake in liver fibrosis. Additionally, the main target cell in healthy conditions, Kupffer cells, are intravascularly located, meaning that the reduced uptake by these cells cannot be explained by changes in the endothelial layer. Excluding these possibilities for the drastic change in carrier uptake, changes of MoMF surface receptors or phagocytic potential might lead to a more specific uptake by these cells. As has been demonstrated previously, MoMF exhibit an increased amount of scavenger receptors in liver fibrosis [50], which could increase carrier uptake by these cells. The observed reduced uptake per cell is likely caused by the increase of total hepatic macrophages in liver fibrosis. The decrease in carrier uptake by hepatic granulocytes might be also attributed to the effect of increased number of macrophages in the liver. Additionally, neutrophils in healthy liver form an intravascular pool, which is not detectable anymore in liver fibrosis, where the majority of granulocytes is residing close to necrotic cells meaning that granulocytes have less access to the carriers after induction of liver fibrosis, which might additionally explain the reduced carrier uptake [51].

\section{Implications of the findings for future applications of nanomedicine}

By analyzing the biodistribution of various carriers in two chronic liver disease models, we demonstrate that the induction of liver fibrosis leads to a distinct change of carrier biodistribution and cellular accumulation. While the liver was, independent of fibrosis, still the prime target organ, some of the carriers (especially polymers and microbubbles) lost part of their targeting properties for myeloid cells. Even liposomes had a drastically lower accumulation per cell in key hepatic macrophage populations in fibrosis. These finding are of great importance when novel nanotherapeutic approaches are planned to be used in patients with liver fibrosis, as dosing and/or targeting moieties might require substantial adjustments in liver fibrosis. On the other hand, all three carrier materials were capable of reaching myeloid cells surrounding areas of liver damage, supporting the principal concept of nanomedicine-based approaches to target macrophages in liver fibrosis [52, 53].

Of the three used carriers, liposomes were most efficiently labeling these inflamed areas, but showed uptake by a broad range of myeloid cells. However, we did not 
directly compare microbubbles or polymers with the same size and zeta potential as liposomes, as the main focus of our study was to enhance the understanding of the effects of liver fibrosis on the biodistribution of drug delivery systems that are typically explored in preclinical and clinical studies. Based on our findings, liposomes could therefore be suited when drugs, such as dexamethasone, should be simultaneously delivered to several immune cell types [6], and/or when drug effect(s) are concentration-dependent. Microbubbles also showed a broad distribution among phagocytic cells after induction of fibrosis. Polymers showed an intermediate distribution, which could be attributed to their inefficient uptake by various cells. Overall, using drug delivery systems in the treatment of chronic liver disease might be feasible and hepatic macrophages are a promising target for this therapeutic approach. Due to the outlined complexity of interaction at the interface of carrier materials and cells, we propose to test the targeting properties of novel carrier molecules because prediction of cellular biodistribution of a novel carrier molecule is not feasible. 


\section{Material and Methods}

\section{Synthesis and characterization of carrier materials}

Microbubbles were synthesized as described previously [18]. N-Butyl cyanoacrylate monomers were titrated to a $1 \%(\mathrm{w} / \mathrm{v})$ TritonX-100 solution at $\mathrm{pH} 2.5$. The dye molecules Rhodamine-B and 1,1,3,3,3,3-Hexamethylindotricarbocyanine (HITC) iodide. This mixture was stirred at 10,000 rpm for $60 \mathrm{~min}$ in an Ultra-turrax (IKAWerke, Germany), which leads to dye-loaded microbubbles with a mean diameter of 2 $\mu \mathrm{m}$ and a shell of poly-Butyl cyanoacrylate. In depth analysis of the PBCA microbubbles used in this study was performed in [54]. The particle size was determined with a Multisizer 3 (Beckmann Coulter). $5 \mu \mathrm{L}$ of MB suspension were diluted in $10 \mathrm{~mL}$ ISOTON II (Beckmann Coulter) at room temperature. The size distribution was $2000 \mathrm{~nm}+/-50 \mathrm{~nm}$. Gel permeation chromatography after lyophilizing and dissolving the microbubbles in chloroform was performed with a HPLC pump (PU2080plus, Jasco) equipped with a refractive index detector (RI-2031plus, Jasco) and an evaporative light scattering detector (PL-ELS-1000, Polymer Laboratories). A polydispersity index (PDI) of $2.1+/-0.1$ was measured.

Liposomes were synthesized as described in [6]. A post-insertion method using 1,2distearoyl-sn-glycero-3-phosphoethanolamine-N-[amino(polyethylene glycol)-2000] (PEG(2000)-DSPE)- and PEG(2000)-DSPE- $\mathrm{NH}_{2}$-based micelles was used for labeling these liposome. NHS esters of Alexa Fluor 750 and Alexa Fluor 488 were covalently linked. During the mixture PEG(2000)-DSPE- $\mathrm{NH}_{2}$ was present in 5-fold excess compared to both fluorophores. These micelles were added to the liposomes and heated for 5 minutes to $60^{\circ} \mathrm{C}$ to form labeled liposomes. Extrusion was used to yield a mean diameter of $100 \mathrm{~nm}$. The particle size was determined by dynamic light scattering with an ALVCGS-3 system (Malvern Instruments, Worcestershire, United Kingdom). The size of the Alexa-488 liposomes is: $119+/-1.3 \mathrm{~nm}$ with a PDI of $0.07+/-0.01$, while the size of the Alexa-750 liposomes is: $121+/-1.2 \mathrm{~nm}$ with a PDI of $0.08+/-0.02$. The zeta potential of PEGylated liposomes was $5.1 \pm 1.4 \mathrm{mV}$ (measured with Zetasizer Nano Z (Malvern Instruments Ltd., Worcs, UK).

Polymer synthesis was performed as described in [26]. By radical copolymerization of (N-2-hydroxypropyl)methacrylamide (HPMA, $85 \mathrm{~mol} \%$ and 3-(Nmethacryloylglycylglycyl) thiazolidine-2-thione (Ma-GG-TT, $15 \mathrm{~mol} \%$ ) in dimethyl sulfoxide (DMSO) at $50^{\circ} \mathrm{C}$ for $6 \mathrm{~h}$ random copolymer precursors were synthesized. 
Poly(HPMA-co-Ma-GG-TT) was dissolved in methanol and $N, N$ Diisopropylethylamine, together with the fluorophores ATTO 488-NH2 and Dy750$\mathrm{NH}_{2}$. The polymer was aminolyzed with 1-aminopropan-2-ol after 30 minutes, followed by precipitation using diethylether and centrifugation. Purification was performed by gel filtration on Sephadex G-25 in water (PD 10 column; Pharmacia). The molecular weight of the polymer was $67 \mathrm{kDa}$, its PDI was 1.7, and the content of both dyes was $2.5 \mathrm{wt} \%$.

\section{Mice}

SKH1-e mice were housed in a specific-pathogen-free environment at the Animal Facility of the University Hospital Aachen. Mice were kept under ethical conditions approved by the appropriate authorities according to German legal requirements (State Agency for Nature, Environment and Consumer Protection in North-Rhine Westphalia, LANUV NRW). Toxicity of the carriers was ruled out using standard assays [6, 26, 55]. All carriers were injected through a tail-vein catheter at a dose of $2 \mathrm{nmol}$ fluorophore dissolved in $100 \mu \mathrm{l} \mathrm{NaCl}$. For the MCD diet model, male mice at an age of 7-8 weeks were kept for 8 weeks on a methionine and choline-deficient diet. For the $\mathrm{CCl}_{4}$ model, mice of mixed gender were injected intraperitoneally with $0.6 \mathrm{ml} / \mathrm{kg}$ body weight of $\mathrm{CCl}_{4}$ (Merck KGaA, Darmstadt, Germany), solved in corn oil, twice-weekly for 6 weeks. Three days before the start of the drug delivery experiment, the diet was changed to chlorophyll-free food (ssniff Spezialdiäten $\mathrm{GmbH}$, Germany), to reduce background fluorescence in the FMT analyses. Mice were euthanized 24 hours after the last $\mathrm{CCl}_{4}$ injection.

\section{Fluorescence-mediated tomography (FMT) and micro-computed tomography $(\mu \mathrm{CT})$}

Optical whole-body imaging was performed before injection of the carriers as well as 15 minutes, 4 , and 24 hours after carrier injection. Fluorescence emission was measured by an FMT-scanner measuring fluorescence emission (FMT2500 LX, PerkinElmer). During imaging, mice were anesthetized using isoflurane $(2 \% \mathrm{v} / \mathrm{v})$ and placed into a custom-made mouse bed for the $\mu \mathrm{CT}$ and FMT scans [25]. For attenuation correction, a $\mu \mathrm{CT}$ was recorded for every time point (Tomoscope Duo, CT-Imaging GmbH, Germany) [56]. Fluorescence was quantified using the Imalytics Preclinical software 
[57]. The combination of FMT with attenuation correction yields comparable quantification as PET-MRI [58]. The total fluorescence intensity was evaluated by normalization to the total fluorescence intensity in the whole mouse 15 minutes after injection. Ex vivo analysis was done after excision of the different organs. Organs were measured in the same setup and data analysis was done with Imalytics Preclinical (Gremse-IT GmbH, Germany). Total fluorescence intensity of the organs is displayed and for spleen the total volume of the segmented spleen was used as a measurement of spleen size.

\section{Flow cytometric analysis}

Flow cytometric analysis of tissue leukocytes was performed as described earlier [12]. Femurs were obtained and perfused to yield bone marrow cells and heart puncture was performed directly post mortem to yield blood cells. The parenchymal organs were digested with collagenase type-IV (Worthington) at $37^{\circ} \mathrm{C}$. Filtering was done on $70 \mu \mathrm{m}$ cell strainers (BD Bioscience) to yield single cell suspensions, and parenchymal cells were removed using sedimentation for 45 minutes at $4{ }^{\circ} \mathrm{C}$ followed by centrifugation for 5 minutes at $4^{\circ} \mathrm{C}$ and $1500 \mathrm{rpm}$. Erythrocyte lysis was done by Pharmlyse (BD Bioscience) and washed with PBS afterwards. Fluorochrome-conjugated antibodies solved in Hank's balanced salt solution (HBSS) containing $0.1 \mathrm{mM}$ EDTA, 2\% bovine serum albumin (BSA) and unconjugated anti-CD16/32 (Fc block, BD) were added to the cell suspension. After 30 minutes unbound antibody was washed with HBSS. 7AAD was added for life/dead discrimination directly before measuring the cells. Staining was performed using the following monoclonal antibodies: Gr-1, CD11b, CD4, CD45, Ly-6G, CD11c (BD Bioscience), CD8a, F4/80 (BD Biosciences), CD8 (Biolegends), I-A ${ }^{\mathrm{b}}, \mathrm{CD} 3, \mathrm{CD} 19, \mathrm{CD} 31$ and F4/80 (eBioscience). Suspensions were measured on a FACS Fortessa (BD Bioscience) and data was analyzed with FlowJo (TreeStar). Flow cytometric data are given as the number of carrier-positive cells of the respective cell type. Microbubbles were excited by a $561 \mathrm{~nm}$ yellow-green laser and recorded with a $582 / 15 \mathrm{~nm}$ filter, polymers and liposomes were excited by a $488 \mathrm{~nm}$ blue laser and recorded with a 530/30 nm filter. Carrier-positive and negative cells segregated clearly in all groups.

\section{Immunohistochemistry and immunofluorescent staining}

Conventional hematoxylin and eosin $(\mathrm{H} \& \mathrm{E})$ and Sirius red stainings were performed 
according to standard protocols [47]. For immunostaining of F4/80, paraffin slides were pre-treated as for H\&E staining (deparaffinization and rehydration), and afterwards the staining was performed according to standard protocols [28]. For immunofluorescent imaging, TissueTek O.C.T. (Sakura Finetek Europe, The Netherlands) embedded and snap-frozen liver tissue was cut into $12 \mu \mathrm{m}$ thick slices and were left to air-dry and fixed in 3\% PFA in PBS for 5 minutes. Rehydration was performed in PBS containing $0.02 \%$ sodiumazide three times for 3 minutes followed by blocking with $1 \%$ BSA in PBS for 5 minutes at RT. Liver sections were stained with directly conjugated rat antimouse CD11b (1:100, BD, Germany) in PBS containing 1\% BSA in a moist chamber overnight. Samples were washed three times for 3 minutes with PBS/sodiumazide and mounted using mounting medium (Vector laboratories, USA) with DAPI to counterstain cell nuclei. All images were recorded on an Axio Imager M2 (Zeiss, Germany).

\section{Statistical Analysis}

Statistical data analysis was performed using Prism software (Version 6, GraphPad Software Inc., La Jolla, CA), and data are expressed as mean \pm standard error of the mean. Differences between groups were assessed by means of a two-tailed unpaired Student $t$ test. P-values were corrected according to Bonferroni-correction, when multiple tests were performed. 


\section{Acknowledgements}

We thank Lia Appold for assistance with microbubble synthesis and characterization.

This work was supported by the German Research Foundation (DFG; Ta434/3-1, SFB/TRR57, SFB 1066, RTG2375), by the European Research Council (ERC Starting Grant 309495 (NeoNaNo), and by the EFRE.NRW initiative (I3-STM). 


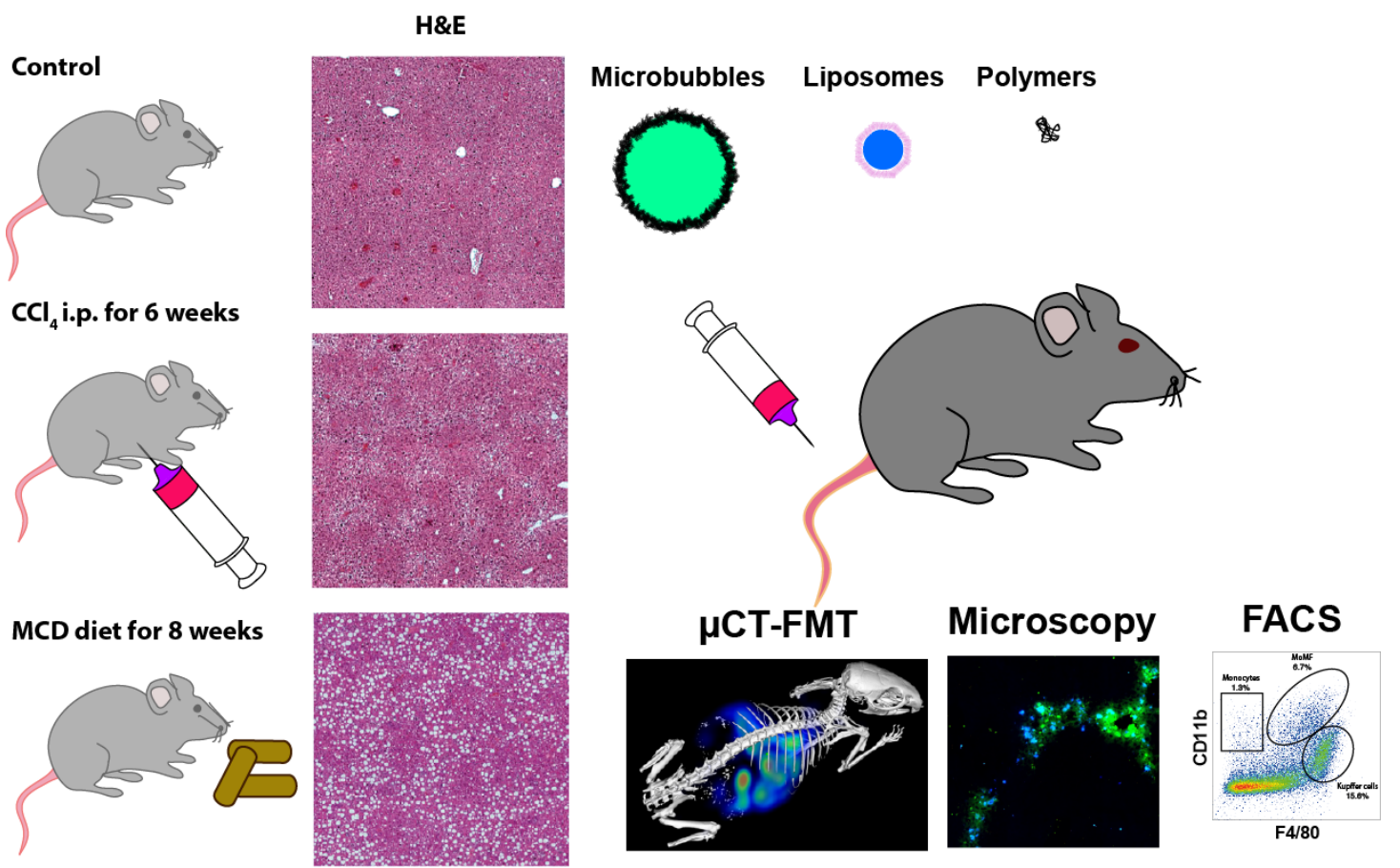

Figure 1. Study design. Liver fibrosis was induced in hairless mice by injection of carbon tetrachloride $\left(\mathrm{CCl}_{4}\right)$ twice weekly for 6 weeks or feeding a methionine cholinedeficient (MCD) diet for 8 weeks. This led to fibrosis and immune cell infiltration in both models and liver steatosis in the MCD model, exemplary histology shown. Mice subjected to these two models as well as healthy control mice were injected intravenously with fluorescently labeled polymers, liposomes or microbubbles. Biodistribution of drug carrier systems was assessed by computed tomographyfluorescence mediated tomography $(\mu \mathrm{CT}-\mathrm{FMT}$ ), flow cytometry (fluorescence activated cell sorting, FACS) of different organs as well as fluorescence microscopy. 


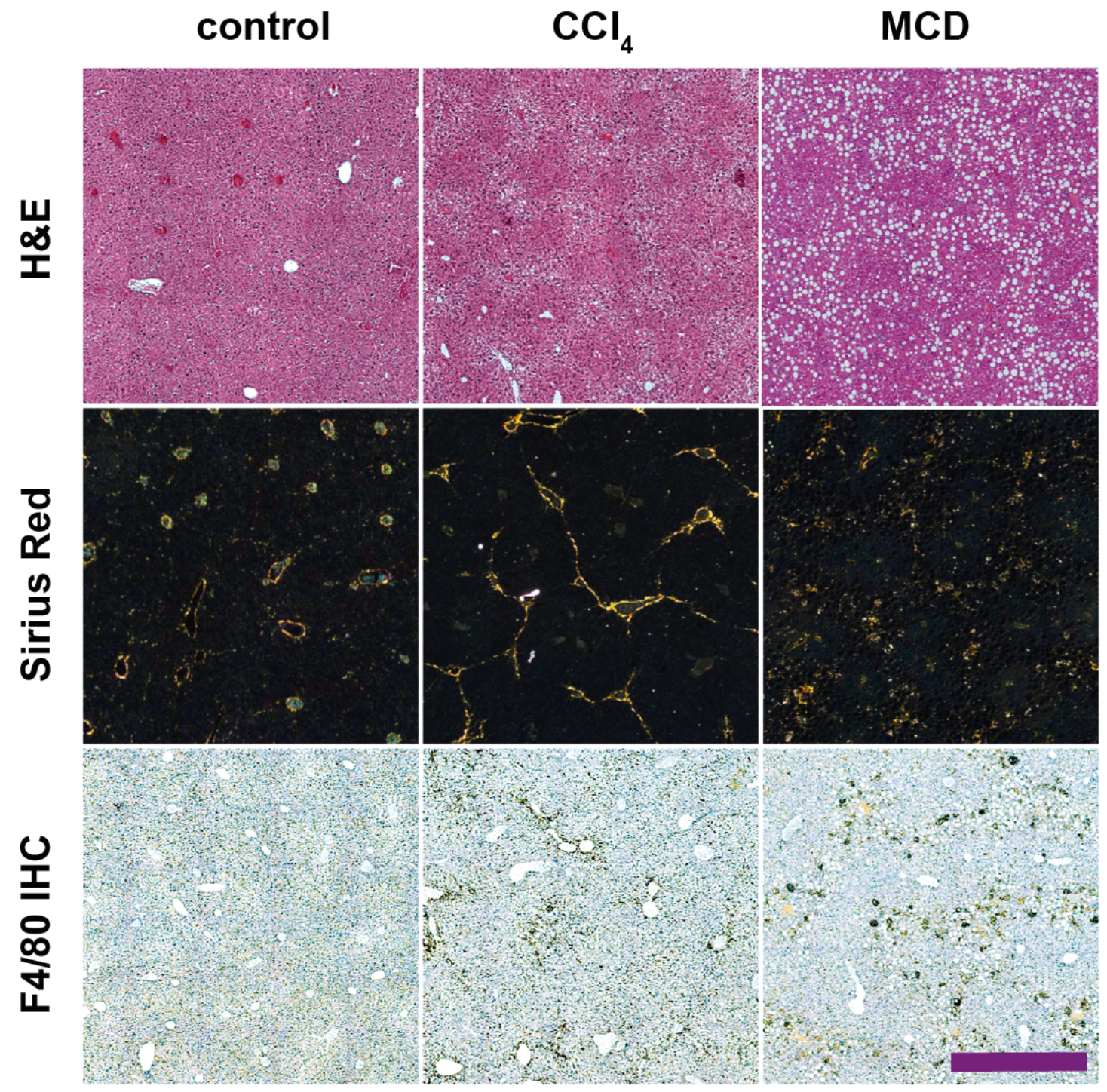

Figure 2. Validation of fibrosis models in hairless mice. Fur-free SKH1-e mice were subjected to the fibrosis models. Hematoxylin and eosin (H\&E) staining was used to assess liver histology, showing patches of necrotic hepatocytes (darker) in $\mathrm{CCl}_{4}$ - and steatotic (white lipid droplets) in MCD diet-treated mice. Sirius Red stains extracellular matrix proteins, demonstrating bridging periportal fibrosis in $\mathrm{CCl}_{4}$ - and perisinusoidal fibrosis in MCD diet treated mice. Immunohistochemistry (IHC) for the macrophage marker $\mathrm{F} 4 / 80$ reveals periportal macrophage accumulation in $\mathrm{CCl}_{4}$-treated mice and more scattered macrophages in the MCD diet model. Representative pictures shown. Scale bar $400 \mu \mathrm{m}$. 


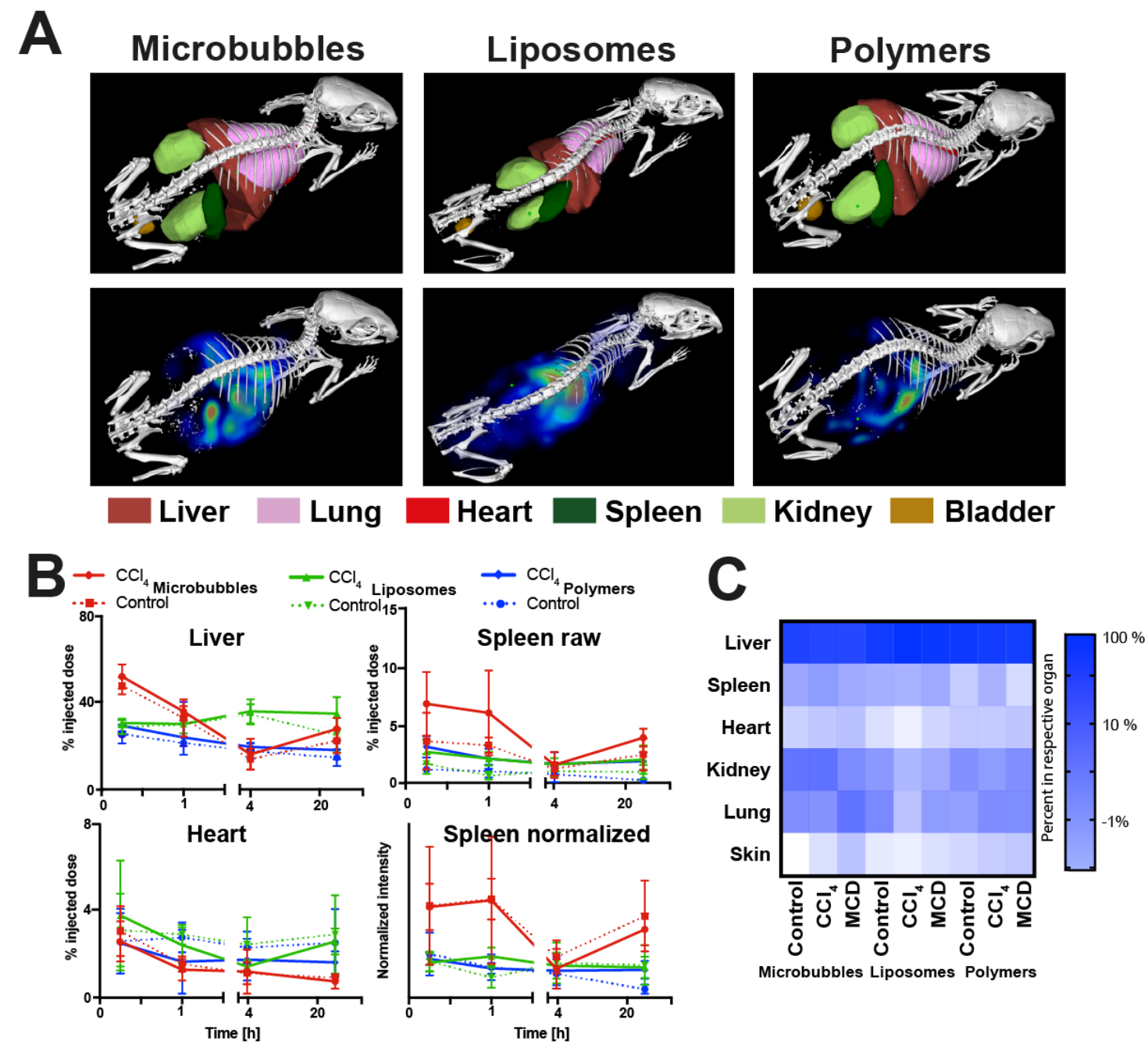

Figure 3. Whole-body biodistribution of drug carriers after induction of liver fibrosis. (A) FMT and $\mu \mathrm{CT}$ were recorded sequentially and fused for analysis. In the upper line, $\mu \mathrm{CT}$ scans are shown overlaid with the organ segmentation. In the lower line, $\mu \mathrm{CT}$ scans 24 hours after carrier injection are shown, overlaid with the FMT signal of $\mathrm{CCl}_{4}$-treated mice. Microbubbles show a high uptake in liver and spleen. Liposomes show the highest signal in the liver. Polymers also show the highest signal in the liver as well as some intestinal signal. (B) Imaging was performed 15 minutes, 1, 4 and 24 hours after particle injection, and the signal is shown for four of the segmented organs (kidney, lung and bladder are shown in Suppl. Fig. 1). Signal is shown as percentage of the measured fluorescence in the body after 15 minutes. Signal after $\mathrm{CCl}_{4}$ administration is shown by solid lines, signal in untreated mice by dotted lines. There was no significant change in the liver and blood signal (segmented as heart) after $\mathrm{CCl}_{4}$ administration. The signal was higher in spleens after induction of fibrosis. However, 
splenomegaly was visible after fibrosis induction. The lower right plot shows the volume-normalized uptake of the various carriers and no difference between the two groups was detectable. (C) For $\mathrm{MCD}, \mathrm{CCl}_{4}$ and healthy mice, we performed ex vivo FMT at $\mathrm{t}=24 \mathrm{~h}$, which showed a similar pattern for the three groups with the various carriers. Heat map is shown in a logarithmic scale. Data shown are derived from $n=5$ animals per condition. 


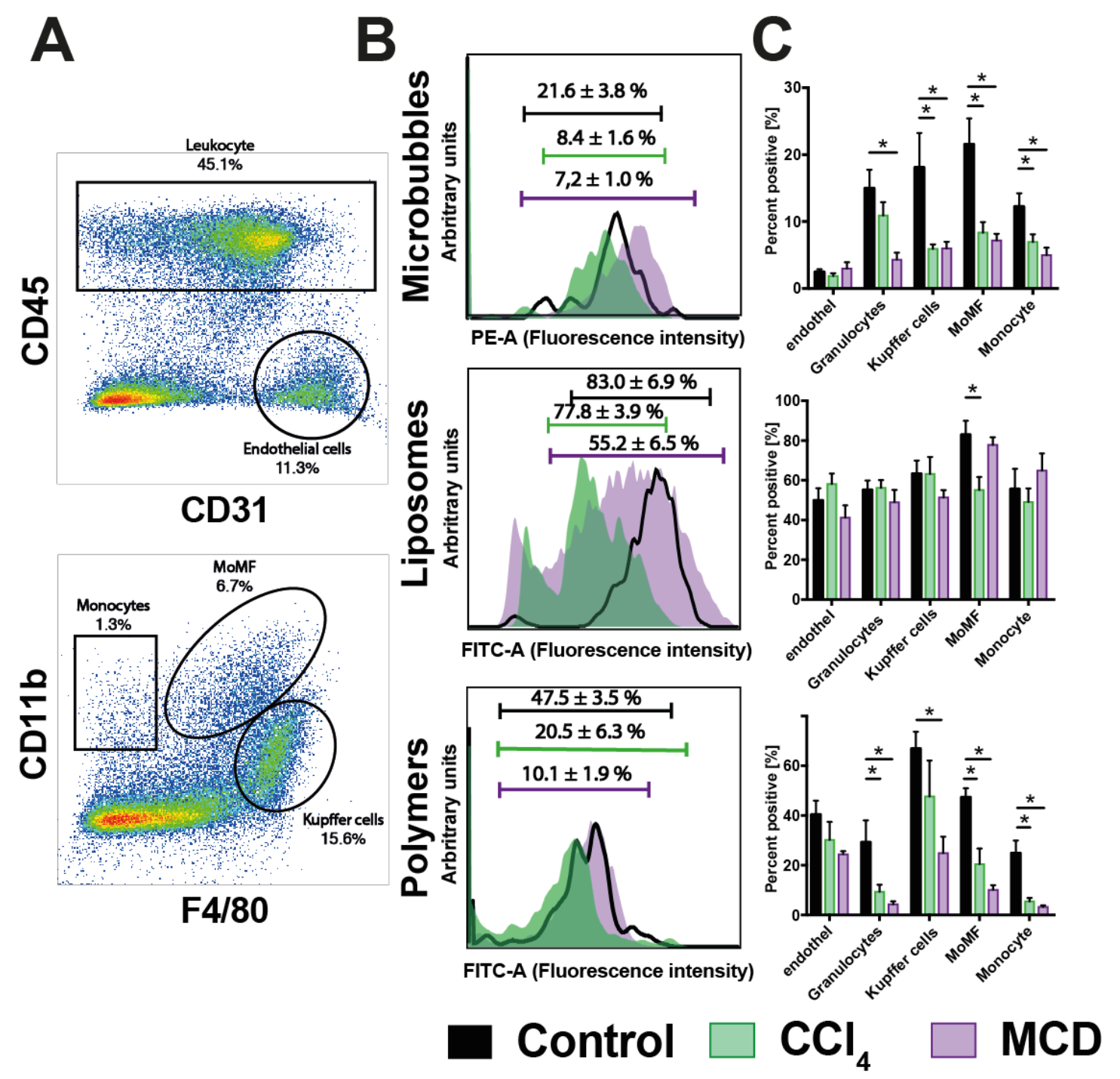

Figure 4. Flow cytometric assessment of carrier distribution in the liver. A) Flow cytometry of non-parenchymal cells of the liver was performed 24 hours after carrier injection. Dead cells were excluded. Leukocyte and liver endothelial cells were detected using CD45 and CD31. Granulocytes were identified using Ly-6G, monocytes, MoMF and Kupffer cells were detected based on CD11b and F4/80 staining (and negative staining for Ly-6G). B) Histograms of carrier fluorescence intensity in MoMF. The plots are area-normalized on the positive fraction. The number of carrierpositive cells is shown. C) Summary of carrier distribution (indicated as percent positive cells in the subset) at 24 hours after injection; significance is shown between control and the two models of liver fibrosis. Data are derived from two independent experiments including 5 mice. $* P<0.05$. 
Blood
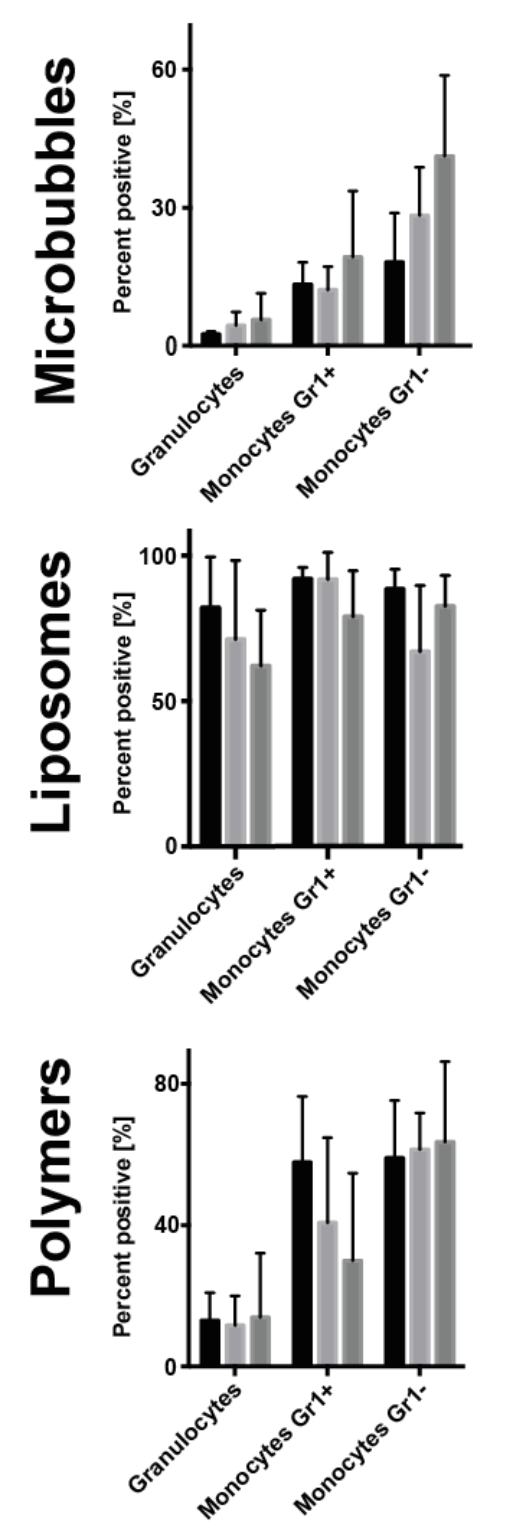

Spleen
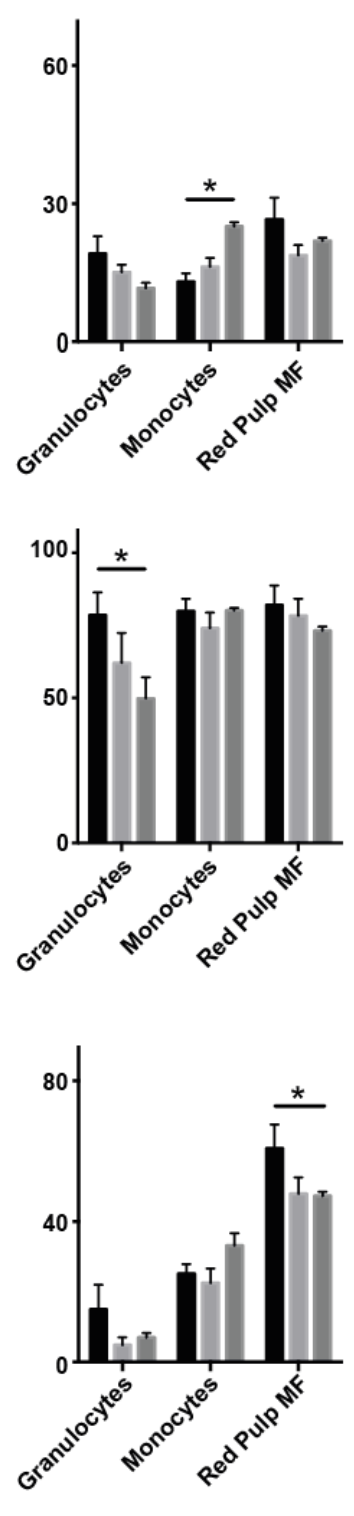

\section{Kidney}
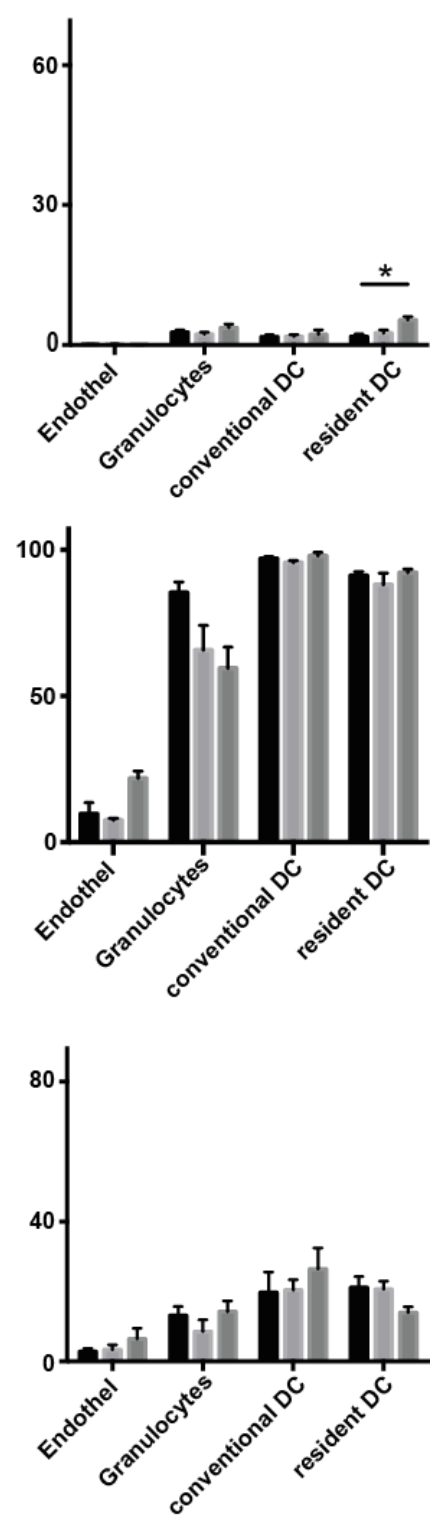

\section{a Control $\mathrm{CCl}_{4} \square \mathrm{MCD}$}

Figure 5. Flow cytometric assessment of carrier distribution in blood, spleen and

kidney. The carrier distribution (indicated as percent positive cells in the subset) was measured 24 hours after injection in control mice and two models of liver fibrosis; significance is shown between control and liver fibrosis. The scaling of the y-axis is adapted for the three carriers allowing comparison of the uptake in the three organs. Data are derived from two independent experiments including 5 mice. $* P<0.05$. 


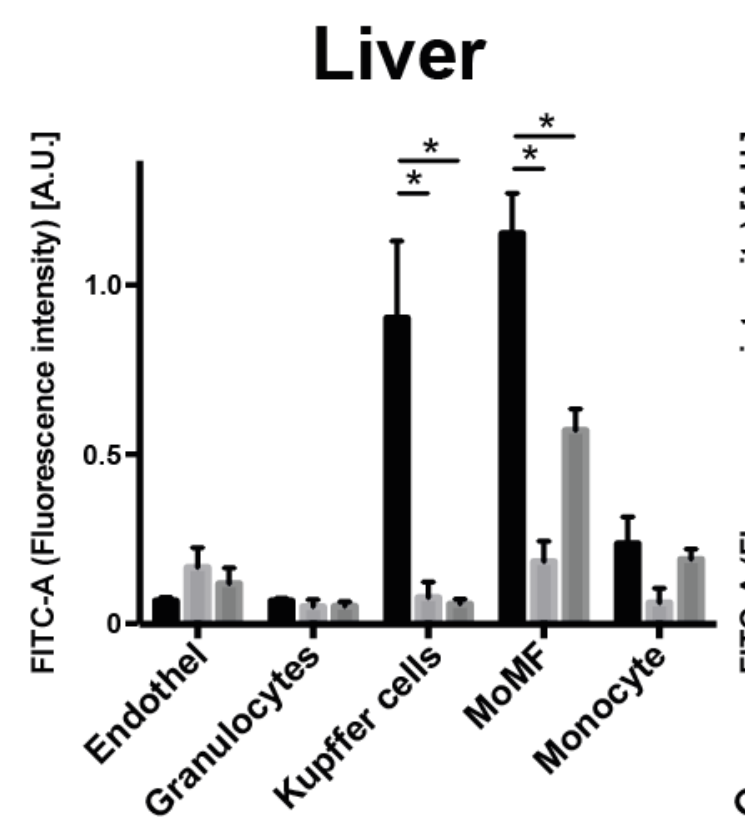

Spleen
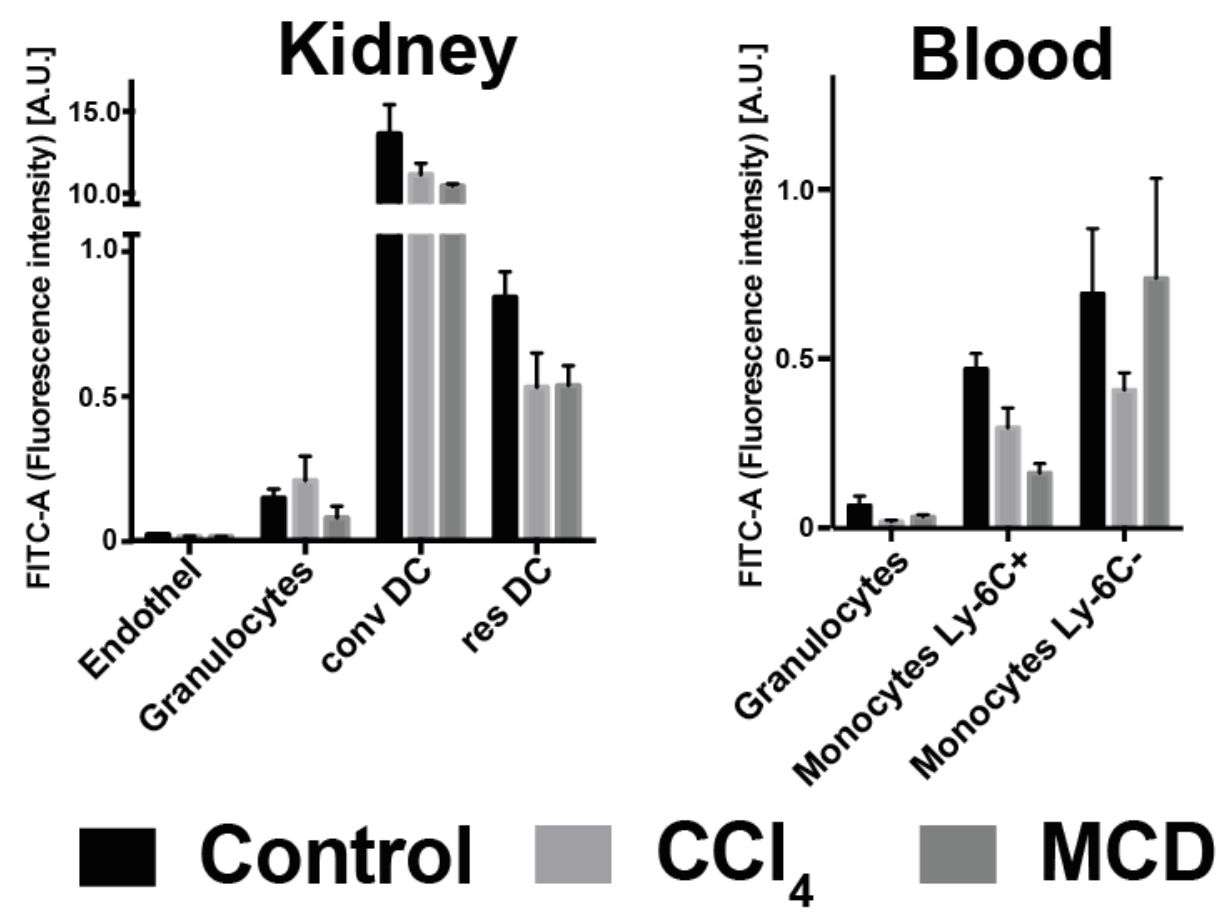

Figure 6. Fluorescence intensity per cell after liposome injection. The carrier distribution (geometric mean of FITC of the respective cell type) was measured 24 hours after injection in control mice and two models of liver fibrosis; significance is shown between control and liver fibrosis. The scaling of the y-axis is the same for every organ. Kidney is displayed with a split axis, because fluorescence in conventional dendritic cells (DC) is about ten times higher compared to every other cell type examined. Data are derived from two independent experiments including 5 mice. $* P$ $<0.05$. 


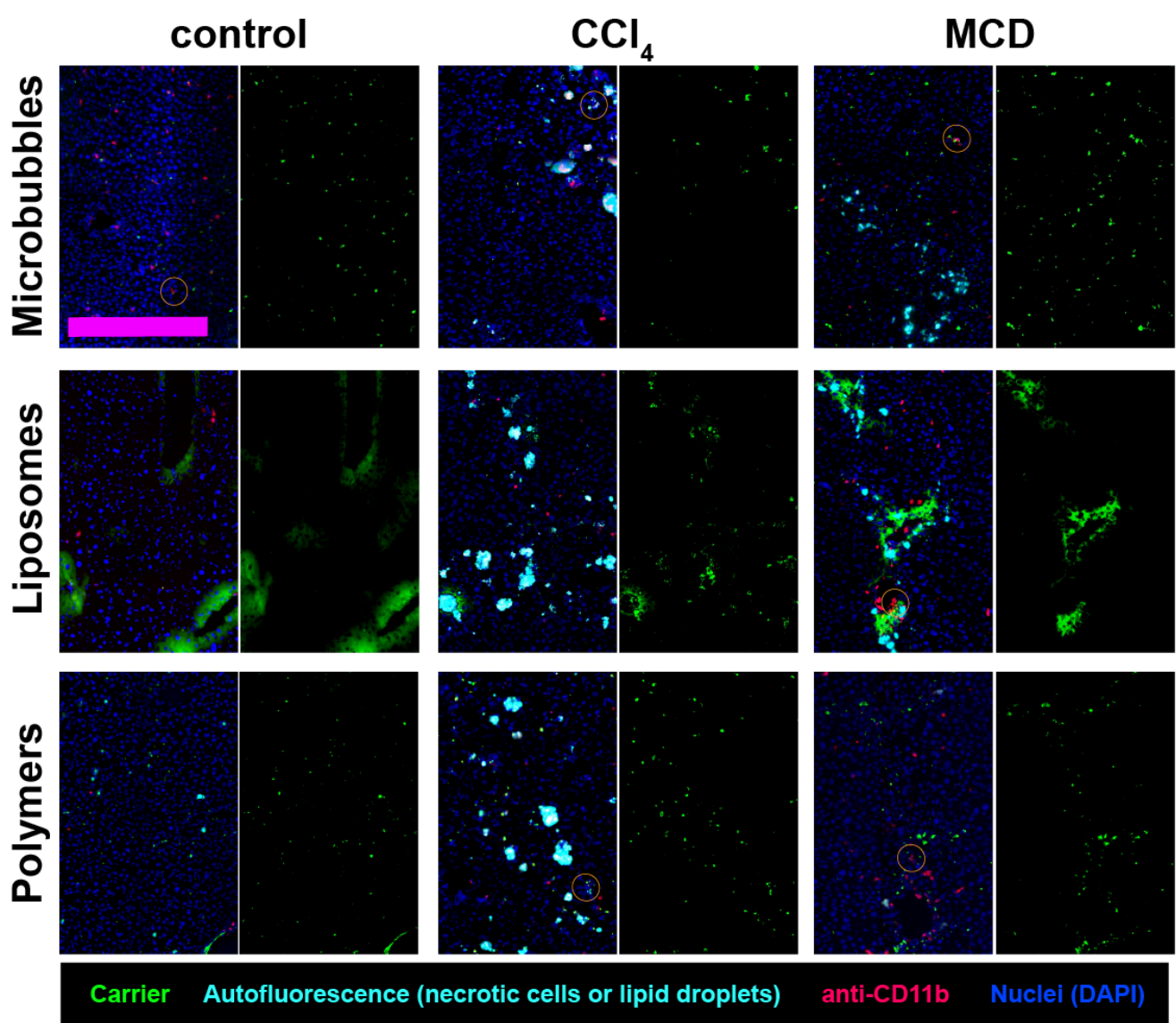

Figure 7. Fluorescence microscopy of intrahepatic carrier distribution. Cryosectioning of snap-frozen liver tissue and staining with anti-CD11b was performed. The carrier is visible in green. Nuclear signal by DAPI is visible in blue, CD11b-staining is visible in red (Alexa Fluor 648). The liposome signal is blurry due to fixation of the tissue slices with methanol. After induction of liver fibrosis with $\mathrm{CCl}_{4}$ (middle column), autofluorescent cells were visible that have the size of hepatocytes, highly suggestive of necrotic cells. In steatohepatitis after MCD treatment, autofluorescence was visible, indicating high fat content in pericentral areas. Fluorescent carriers were visible in the areas with higher damage in liver fibrosis models. Microbubbles, liposomes and polymers show a periportal distribution in $\mathrm{CCl}_{4}-$ induced liver fibrosis and a pericentral distribution in MCD-induced steatohepatitis. Scale bar $400 \mu \mathrm{m}$. 

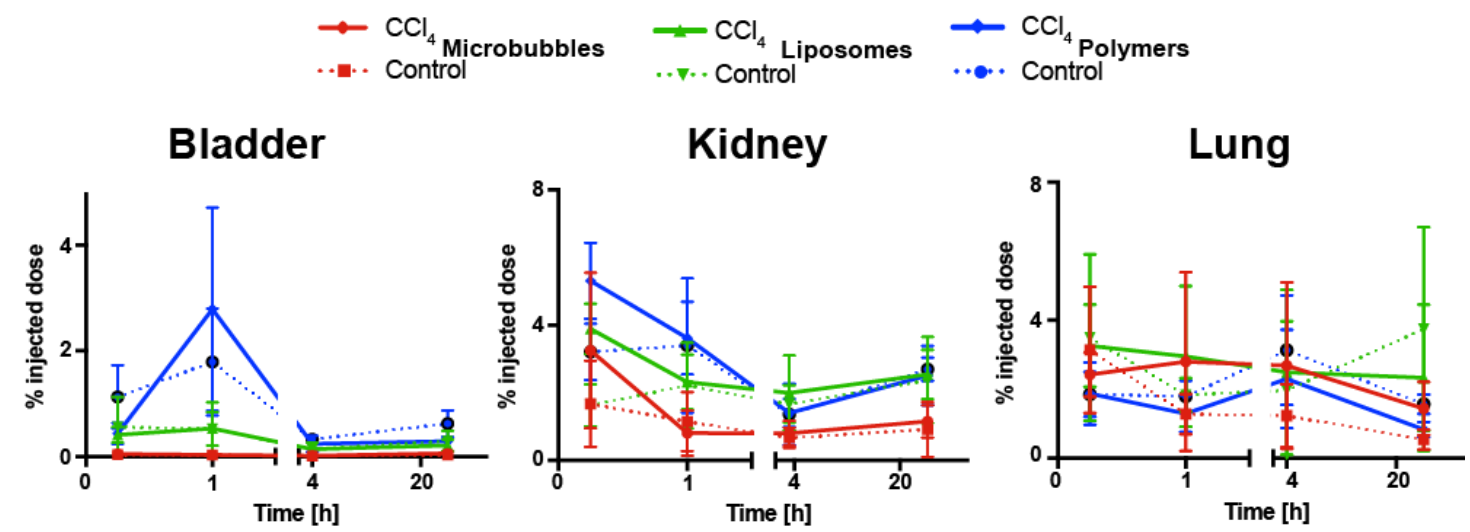

Supplementary Figure 1. Kinetic analysis of carrier uptake by $\mu$ CT-FMT of other organs. Imaging was performed 15 minutes, 4, and 24 hours after carrier injection. The signal is shown for bladder, kidney and lung. All organs showed lower uptake compared to the liver (Fig. 3). There was a peak of signal after injection of polymers in the bladder after one hour, showing renally excreted polymers. There was no significant difference between the signal in control and $\mathrm{CCl}_{4}$ treated mice. 

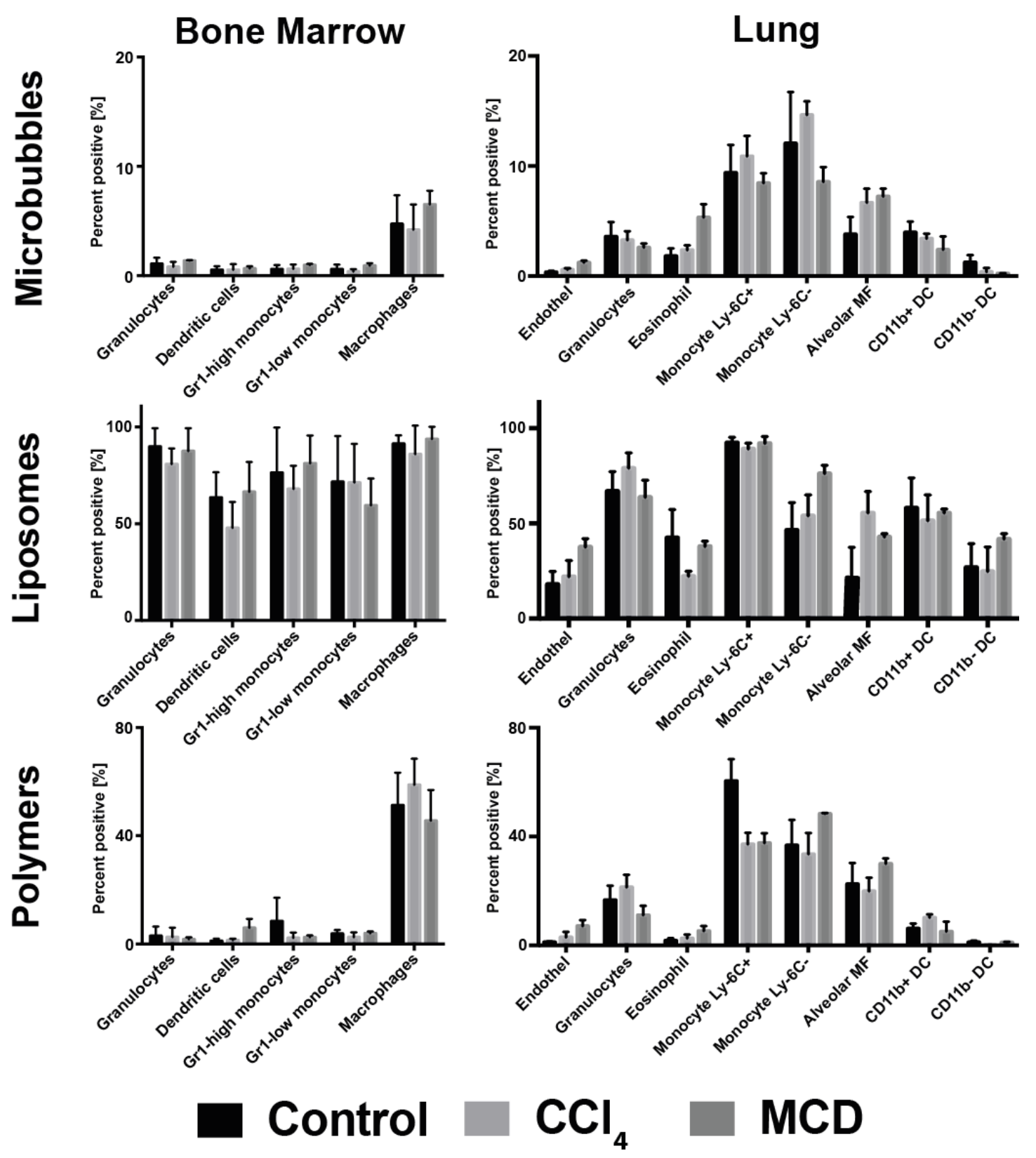

Supplementary Figure 2. Flow cytometric assessment of carrier distribution in lung and bone marrow. The carrier distribution (indicated as percent positive cells in the subset) was measured 24 hours after injection in control mice and two models of liver fibrosis; significance is shown between control and liver fibrosis. The scaling of the y-axis is adapted for the three carriers allowing comparison of the uptake in the different organs. Data are derived from two independent experiments including 5 mice. $* P<0.05$. 


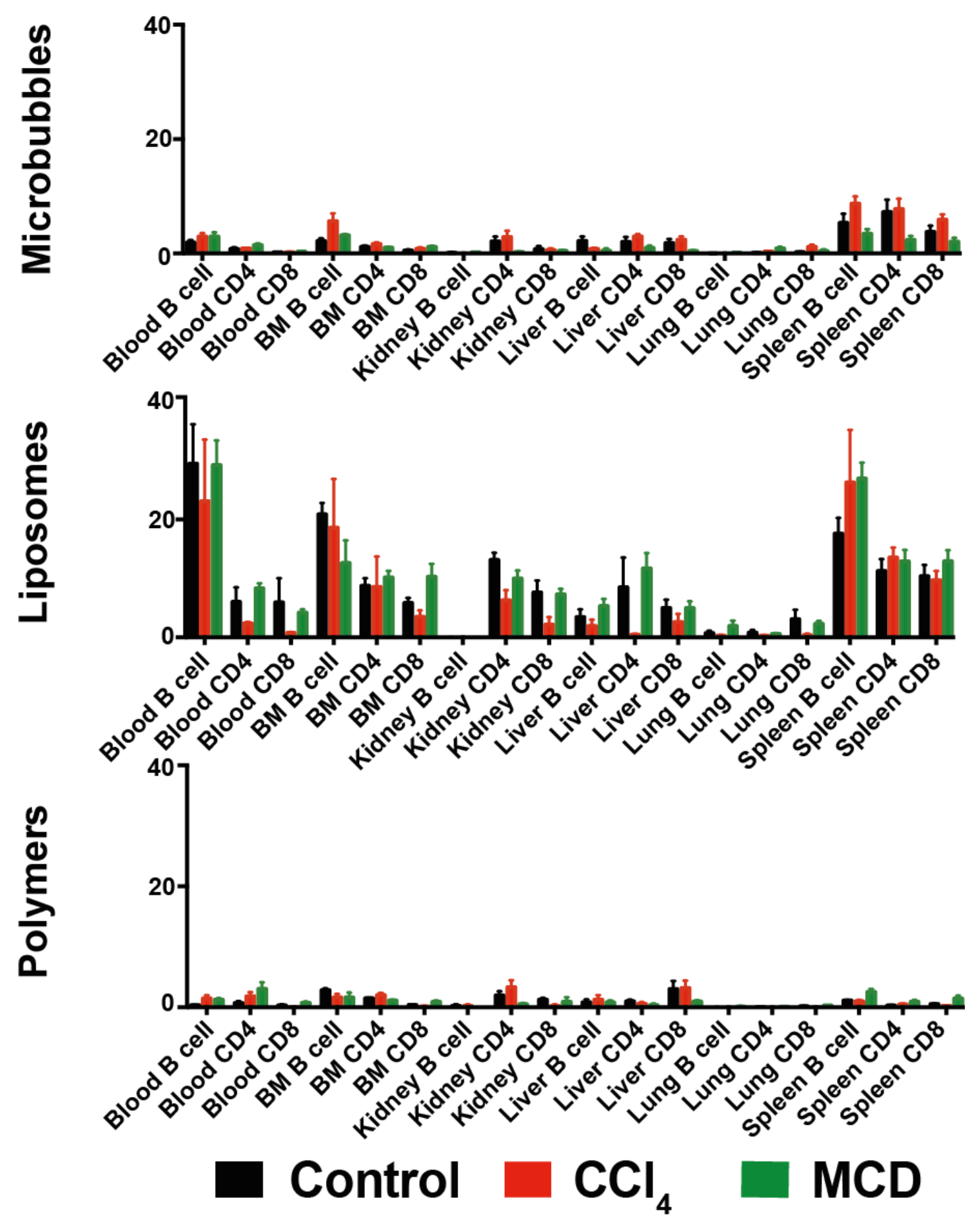

Supplementary Figure 3. Flow cytometric assessment of carrier distribution in lymphocytes. The carrier distribution (indicated as percent positive cells in the subset) was measured 24 hours after injection in control mice and two models of liver fibrosis; no comparison between control and liver fibrosis was significant. The scaling of the yaxis is adapted for the three carriers allowing comparison of the uptake in the different organs. Data are derived from two independent experiments including 5 mice. ${ }^{*} P<$ 0.05 . 


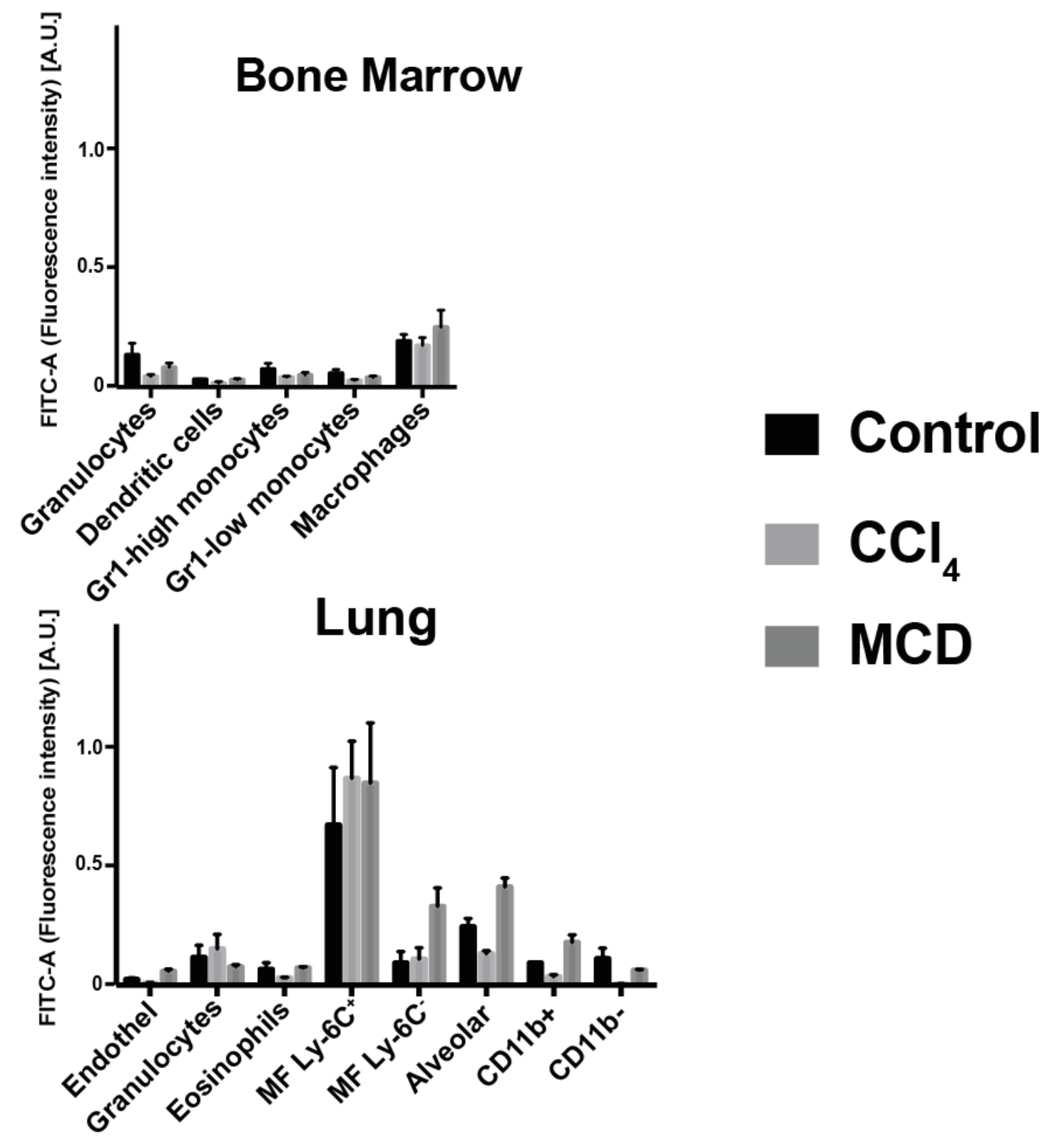

Supplementary Figure 4. Fluorescence intensity of cells after liposome injection.

The carrier distribution (geometric mean of FITC of the respective cell type) was measured 24 hours after injection in control mice and two models of liver fibrosis; significance is shown between control and liver fibrosis. The scaling of the y-axis is the same for every organ. Data are derived from 2 independent experiments including 5 mice. $* P<0.05$. 

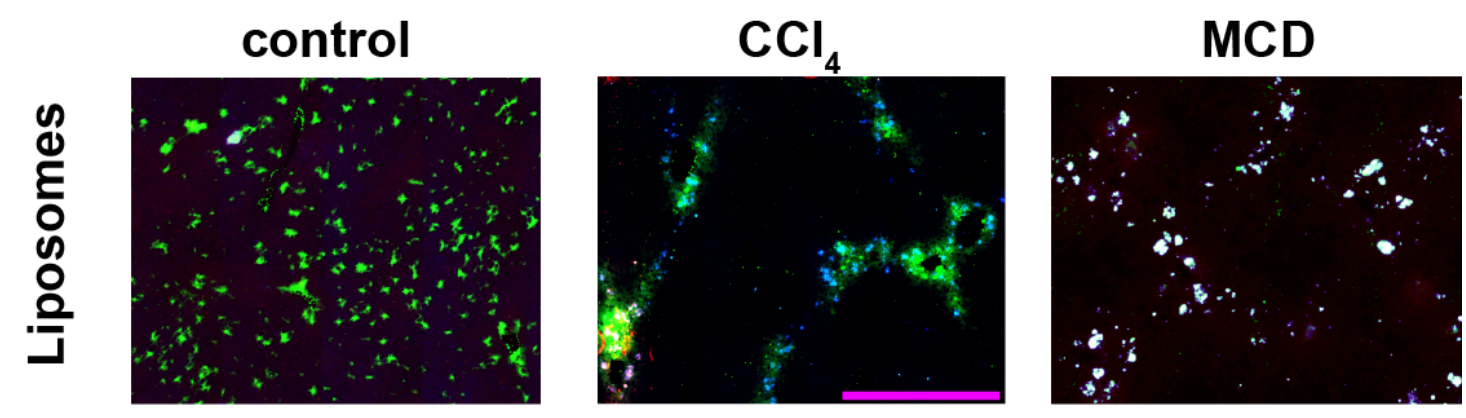

\section{Liposomes Necrotic cells Lipid-laden cells}

Supplementary Figure 5. Fluorescence microscopy of intrahepatic carrier distribution. Cryosectioning of snap-frozen liver tissue. Displayed is the liposome signal directly after slicing the liver tissue, without further processing or DAPI-staining to prevent dissolvement of the fluorophore. In control mice, there is a broad distribution of carrier positive-cells that resemble sinusoid structures (indicative of uptake by Kupffer and endothelial cells). After $\mathrm{CCl}_{4}$ induced liver damage, only periportal cells show a high uptake. Turquoise cells are autofluorescent necrotic cells. After MCD induced liver damage, there is a pericentral distribution of carrier positive cells that show at the same time a high autofluorescence (green dots in purple-white cells), indicating carrier uptake by lipid-laden macrophages. Scale bar $400 \mu \mathrm{m}$. 
[1] R. Weiskirchen, S. Weiskirchen, F. Tacke, Recent advances in understanding liver fibrosis: bridging basic science and individualized treatment concepts, F1000Res 7 (2018) 10.12688/f1000research.14841.1.

[2] Z. Younossi, F. Tacke, M. Arrese, B.C. Sharma, I. Mostafa, E. Bugianesi, V.W. Wong, Y. Yilmaz, J. George, J. Fan, M.B. Vos, Global Perspectives on Non-alcoholic Fatty Liver Disease and Non-alcoholic Steatohepatitis, Hepatology (2018) 10.1002/hep.30251.

[3] S.L. Friedman, B.A. Neuschwander-Tetri, M. Rinella, A.J. Sanyal, Mechanisms of NAFLD development and therapeutic strategies, Nat Med 24(7) (2018) 908922 10.1038/s41591-018-0104-9.

[4] F. Tacke, R. Weiskirchen, An update on the recent advances in antifibrotic therapy, Expert Rev Gastroenterol Hepatol (2018) 1-10 10.1080/17474124.2018.1530110.

[5] M. Bartneck, K.T. Warzecha, F. Tacke, Therapeutic targeting of liver inflammation and fibrosis by nanomedicine, Hepatobiliary Surg Nutr 3(6) (2014) 364-76 10.3978/j.issn.2304-3881.2014.11.02.

[6] M. Bartneck, K.M. Scheyda, K.T. Warzecha, L.Y. Rizzo, K. Hittatiya, T. Luedde, G. Storm, C. Trautwein, T. Lammers, F. Tacke, Fluorescent cell-traceable dexamethasone-loaded liposomes for the treatment of inflammatory liver diseases, Biomaterials 37 (2015) 367-82 10.1016/j.biomaterials.2014.10.030. [7] A.K. Bera, T. Rana, S. Das, S. Bandyopadhyay, D. Bhattacharya, D. Pan, S. De, S.K. Das, L-Ascorbate protects rat hepatocytes against sodium arsenite--induced cytotoxicity and oxidative damage, Hum Exp Toxicol 29(2) (2010) 103-11 10.1177/0960327109357215.

[8] A. Carambia, B. Freund, D. Schwinge, O.T. Bruns, S.C. Salmen, H. Ittrich, R. Reimer, M. Heine, S. Huber, C. Waurisch, A. Eychmuller, D.C. Wraith, T. Korn, P. Nielsen, H. Weller, C. Schramm, S. Luth, A.W. Lohse, J. Heeren, J. Herkel, Nanoparticle-based autoantigen delivery to Treg-inducing liver sinusoidal endothelial cells enables control of autoimmunity in mice, J Hepatol 62(6) (2015) 1349-56 10.1016/j.jhep.2015.01.006.

[9] J.M. Luk, Q.S. Zhang, N.P. Lee, J.Y. Wo, P.P. Leung, L.X. Liu, M.Y. Hu, K.F. Cheung, C.K. Hui, G.K. Lau, S.T. Fan, Hepatic stellate cell-targeted delivery of M6P-HSAglycyrrhetinic acid attenuates hepatic fibrogenesis in a bile duct ligation rat model, Liver Int 27(4) (2007) 548-57 10.1111/j.1478-3231.2007.01452.x. [10] B.N. Melgert, P. Olinga, J.M. Van Der Laan, B. Weert, J. Cho, D. Schuppan, G.M. Groothuis, D.K. Meijer, K. Poelstra, Targeting dexamethasone to Kupffer cells: effects on liver inflammation and fibrosis in rats, Hepatology 34(4 Pt 1) (2001) 719-28 10.1053/jhep.2001.27805.

[11] H.T. Schon, M. Bartneck, E. Borkham-Kamphorst, J. Nattermann, T. Lammers, F. Tacke, R. Weiskirchen, Pharmacological Intervention in Hepatic Stellate Cell Activation and Hepatic Fibrosis, Front Pharmacol 7 (2016) 33 10.3389/fphar.2016.00033.

[12] C. Ergen, F. Heymann, W. Al Rawashdeh, F. Gremse, M. Bartneck, U. Panzer, R. Pola, M. Pechar, G. Storm, N. Mohr, M. Barz, R. Zentel, F. Kiessling, C. Trautwein, T. Lammers, F. Tacke, Targeting distinct myeloid cell populations in vivo using polymers, liposomes and microbubbles, Biomaterials 114 (2017) 106-120 10.1016/j.biomaterials.2016.11.009. 
[13] B.G. Lopez, M.S. Tsai, J.L. Baratta, K.J. Longmuir, R.T. Robertson, Characterization of Kupffer cells in livers of developing mice, Comp Hepatol 10(1) (2011) 2 10.1186/1476-5926-10-2.

[14] F. Tacke, Targeting hepatic macrophages to treat liver diseases, J Hepatol 66(6) (2017) 1300-1312 10.1016/j.jhep.2017.02.026.

[15] F. Heymann, J. Peusquens, I. Ludwig-Portugall, M. Kohlhepp, C. Ergen, P. Niemietz, C. Martin, N. van Rooijen, J.C. Ochando, G.J. Randolph, T. Luedde, F. Ginhoux, C. Kurts, C. Trautwein, F. Tacke, Liver inflammation abrogates immunological tolerance induced by Kupffer cells, Hepatology 62(1) (2015) 27991 10.1002/hep.27793.

[16] O. Krenkel, F. Tacke, Liver macrophages in tissue homeostasis and disease, Nat Rev Immunol 17(5) (2017) 306-321 10.1038/nri.2017.11.

[17] R. Pola, M. Studenovsky, M. Pechar, K. Ulbrich, O. Hovorka, D. Vetvicka, B. Rihova, HPMA-copolymer conjugates targeted to tumor endothelium using synthetic oligopeptides, Journal of Drug Targeting 17(10) (2009) 763-776 10.3109/10611860903115282.

[18] P. Koczera, L. Appold, Y. Shi, M. Liu, A. Dasgupta, V. Pathak, T. Ojha, S. Fokong, Z. Wu, M. van Zandvoort, O. Iranzo, A.J.C. Kuehne, A. Pich, F. Kiessling, T. Lammers, PBCA-based polymeric microbubbles for molecular imaging and drug delivery, J Control Release 259 (2017) 128-135 10.1016/j.jconrel.2017.03.006. [19] A.E. Nel, L. Mädler, D. Velegol, T. Xia, E.M.V. Hoek, P. Somasundaran, F. Klaessig, V. Castranova, M. Thompson, Understanding biophysicochemical interactions at the nano-bio interface, Nature Materials 8 (2009) 543 $10.1038 /$ nmat 2442 .

[20] E. Blanco, H. Shen, M. Ferrari, Principles of nanoparticle design for overcoming biological barriers to drug delivery, Nature Biotechnology 33 (2015) 941 10.1038/nbt.3330.

[21] D.A. Kuhn, D. Vanhecke, B. Michen, F. Blank, P. Gehr, A. Petri-Fink, B. RothenRutishauser, Different endocytotic uptake mechanisms for nanoparticles in epithelial cells and macrophages, Beilstein Journal of Nanotechnology 5 (2014) 1625-1636 10.3762/bjnano.5.174.

[22] J.I. Fortea, C. Fernandez-Mena, M. Puerto, C. Ripoll, J. Almagro, J. Banares, J.M. Bellon, R. Banares, J. Vaquero, Comparison of Two Protocols of Carbon Tetrachloride-Induced Cirrhosis in Rats - Improving Yield and Reproducibility, Sci Rep 8(1) (2018) 9163 10.1038/s41598-018-27427-9.

[23] A.R. Rincon, A. Covarrubias, J. Pedraza-Chaverri, J.L. Poo, J. ArmendarizBorunda, A. Panduro, Differential effect of $\mathrm{CCl} 4$ on renal function in cirrhotic and non-cirrhotic rats, Exp Toxicol Pathol 51(3) (1999) 199-205 10.1016/S09402993(99)80094-3.

[24] M. Ubeda, L. Munoz, M.J. Borrero, D. Diaz, R. Frances, J. Monserrat, M. Lario, L. Lledo, J. Such, M. Alvarez-Mon, A. Albillos, Critical role of the liver in the induction of systemic inflammation in rats with preascitic cirrhosis, Hepatology 52 (6) (2010) 2086-95 10.1002/hep.23961.

[25] F. Gremse, D. Doleschel, S. Zafarnia, A. Babler, W. Jahnen-Dechent, T. Lammers, W. Lederle, F. Kiessling, Hybrid microCT-FMT imaging and image analysis, J Vis Exp (100) (2015) e52770 10.3791/52770.

[26] S. Kunjachan, F. Gremse, B. Theek, P. Koczera, R. Pola, M. Pechar, T. Etrych, K. Ulbrich, G. Storm, F. Kiessling, T. Lammers, Noninvasive optical imaging of 
nanomedicine biodistribution, ACS Nano 7(1) (2013) 252-62

$10.1021 /$ nn303955n.

[27] D. Scholten, J. Trebicka, C. Liedtke, R. Weiskirchen, The carbon tetrachloride model in mice, Lab Anim 49(1 Suppl) (2015) 4-11 10.1177/0023677215571192. [28] 0. Krenkel, T. Puengel, O. Govaere, A.T. Abdallah, J.C. Mossanen, M. Kohlhepp, A. Liepelt, E. Lefebvre, T. Luedde, C. Hellerbrand, R. Weiskirchen, T. Longerich, I.G. Costa, Q.M. Anstee, C. Trautwein, F. Tacke, Therapeutic inhibition of inflammatory monocyte recruitment reduces steatohepatitis and liver fibrosis, Hepatology 67(4) (2018) 1270-1283 10.1002/hep.29544.

[29] C. Baeck, A. Wehr, K.R. Karlmark, F. Heymann, M. Vucur, N. Gassler, S. Huss, S. Klussmann, D. Eulberg, T. Luedde, C. Trautwein, F. Tacke, Pharmacological inhibition of the chemokine CCL2 (MCP-1) diminishes liver macrophage infiltration and steatohepatitis in chronic hepatic injury, Gut 61(3) (2012) 41626 10.1136/gutjnl-2011-300304.

[30] S. Kunjachan, J. Ehling, G. Storm, F. Kiessling, T. Lammers, Noninvasive Imaging of Nanomedicines and Nanotheranostics: Principles, Progress, and Prospects, Chemical Reviews 115(19) (2015) 10907-10937 10.1021/cr500314d. [31] B.S. Schaffer, M.H. Grayson, J.M. Wortham, C.B. Kubicek, A.T. McCleish, S.I. Prajapati, L.D. Nelon, M.M. Brady, I. Jung, T. Hosoyama, L.M. Sarro, M.A. Hanes, B.P. Rubin, J.E. Michalek, C.B. Clifford, A.J. Infante, C. Keller, Immune competency of a hairless mouse strain for improved preclinical studies in genetically engineered mice, Mol Cancer Ther 9(8) (2010) 2354-64 10.1158/15357163.MCT-10-0207.

[32] C. Baeck, X. Wei, M. Bartneck, V. Fech, F. Heymann, N. Gassler, K. Hittatiya, D. Eulberg, T. Luedde, C. Trautwein, F. Tacke, Pharmacological inhibition of the chemokine $\mathrm{C}-\mathrm{C}$ motif chemokine ligand 2 (monocyte chemoattractant protein 1 ) accelerates liver fibrosis regression by suppressing Ly-6C(+) macrophage infiltration in mice, Hepatology 59(3) (2014) 1060-72 10.1002/hep.26783. [33] A. Albillos, M. Lario, M. Alvarez-Mon, Cirrhosis-associated immune dysfunction: distinctive features and clinical relevance, J Hepatol 61(6) (2014) 1385-96 10.1016/j.jhep.2014.08.010.

[34] K. Schledzewski, C. Geraud, B. Arnold, S. Wang, H.J. Grone, T. Kempf, K.C. Wollert, B.K. Straub, P. Schirmacher, A. Demory, H. Schonhaber, A. Gratchev, L. Dietz, H.J. Thierse, J. Kzhyshkowska, S. Goerdt, Deficiency of liver sinusoidal scavenger receptors stabilin-1 and - 2 in mice causes glomerulofibrotic nephropathy via impaired hepatic clearance of noxious blood factors, J Clin Invest 121(2) (2011) 703-14 10.1172/JCI44740.

[35] L. Li, M. Duan, W. Chen, A. Jiang, X. Li, J. Yang, Z. Li, The spleen in liver cirrhosis: revisiting an old enemy with novel targets, J Transl Med 15(1) (2017) 111 10.1186/s12967-017-1214-8.

[36] S.H.A. Shah, P.C. Hayes, P.L. Allan, J. Nicoll, N.D. Finlayson, Measurement of spleen size and its relation to hypersplenism and portal hemodynamics in portal hypertension due to hepatic cirrhosis, American Journal of Gastroenterology 91(12) (1996) 2580-2583, <Go to ISI>://WOS:A1996VW76600025.

[37] S. Ren, S. Zhang, M. Li, C. Huang, R. Liang, A. Jiang, Y. Guo, Y. Pu, N. Huang, J. Yang, Z. Li, NF-kappaB p65 and c-Rel subunits promote phagocytosis and cytokine secretion by splenic macrophages in cirrhotic patients with hypersplenism, Int J Biochem Cell Biol 45(2) (2013) 335-43 10.1016/j.biocel.2012.11.012. 
[38] F. Tacke, F. Ginhoux, C. Jakubzick, N. van Rooijen, M. Merad, G.J. Randolph, Immature monocytes acquire antigens from other cells in the bone marrow and present them to T cells after maturing in the periphery, J Exp Med 203(3) (2006) 583-97 10.1084/jem.20052119.

[39] B. Ravishankar, R. Shinde, H. Liu, K. Chaudhary, J. Bradley, H.P. Lemos, P. Chandler, M. Tanaka, D.H. Munn, A.L. Mellor, T.L. McGaha, Marginal zone CD169+ macrophages coordinate apoptotic cell-driven cellular recruitment and tolerance, Proc Natl Acad Sci U S A 111(11) (2014) 4215-20 10.1073/pnas.1320924111.

[40] H. Veninga, E.G. Borg, K. Vreeman, P.R. Taylor, H. Kalay, Y. van Kooyk, G. Kraal, L. Martinez-Pomares, J.M. den Haan, Antigen targeting reveals splenic CD169+ macrophages as promoters of germinal center B-cell responses, Eur J Immunol 45(3) (2015) 747-57 10.1002/eji.201444983.

[41] J. Hundertmark, O. Krenkel, F. Tacke, Adapted Immune Responses of Myeloid-Derived Cells in Fatty Liver Disease, Front Immunol 9 (2018) 2418 10.3389/fimmu.2018.02418.

[42] D. Kurotaki, T. Uede, T. Tamura, Functions and development of red pulp macrophages, Microbiol Immunol 59(2) (2015) 55-62 10.1111/13480421.12228.

[43] F.K. Swirski, M. Nahrendorf, M. Etzrodt, M. Wildgruber, V. Cortez-Retamozo, P. Panizzi, J.L. Figueiredo, R.H. Kohler, A. Chudnovskiy, P. Waterman, E. Aikawa, T.R. Mempel, P. Libby, R. Weissleder, M.J. Pittet, Identification of splenic reservoir monocytes and their deployment to inflammatory sites, Science 325(5940) (2009) 612-6 10.1126/science.1175202.

[44] C. Gottschalk, C. Kurts, The Debate about Dendritic Cells and Macrophages in the Kidney, Front Immunol 6 (2015) 435 10.3389/fimmu.2015.00435.

[45] R. Zaynagetdinov, T.P. Sherrill, P.L. Kendall, B.H. Segal, K.P. Weller, R.M. Tighe, T.S. Blackwell, Identification of myeloid cell subsets in murine lungs using flow cytometry, American Journal of Respiratory Cell and Molecular Biology 49(2) (2013) 180-9 10.1165/rcmb.2012-0366MA.

[46] A. Jindal, S. Bruzzi, S. Sutti, I. Locatelli, C. Bozzola, C. Paternostro, M. Parola, E. Albano, Fat-laden macrophages modulate lobular inflammation in nonalcoholic steatohepatitis (NASH), Exp Mol Pathol 99(1) (2015) 155-62 10.1016/j.yexmp.2015.06.015.

[47] K.R. Karlmark, R. Weiskirchen, H.W. Zimmermann, N. Gassler, F. Ginhoux, C. Weber, M. Merad, T. Luedde, C. Trautwein, F. Tacke, Hepatic recruitment of the inflammatory Gr1+ monocyte subset upon liver injury promotes hepatic fibrosis, Hepatology 50(1) (2009) 261-74 10.1002/hep.22950.

[48] L. Li, Z. Hu, W. Li, M. Hu, J. Ran, P. Chen, Q. Sun, Establishment of a standardized liver fibrosis model with different pathological stages in rats, Gastroenterology research and practice 2012 (2012) 560345 $10.1155 / 2012 / 560345$.

[49] P. Konigshofer, K. Brusilovskaya, P. Schwabl, T. Reiberger, Animal models of portal hypertension, Biochim Biophys Acta Mol Basis Dis (2018) 10.1016/j.bbadis.2018.07.018.

[50] L. Beljaars, M. Schippers, C. Reker-Smit, F.O. Martinez, L. Helming, K. Poelstra, B.N. Melgert, Hepatic Localization of Macrophage Phenotypes during Fibrogenesis and Resolution of Fibrosis in Mice and Humans, Frontiers in Immunology 5(430) (2014) 10.3389/fimmu.2014.00430. 
[51] C. Summers, S.M. Rankin, A.M. Condliffe, N. Singh, A.M. Peters, E.R. Chilvers, Neutrophil kinetics in health and disease, Trends in immunology 31(8) (2010) 318-24 10.1016/j.it.2010.05.006.

[52] S. Poilil Surendran, R. George Thomas, M.J. Moon, Y.Y. Jeong, Nanoparticles for the treatment of liver fibrosis, Int J Nanomedicine 12 (2017) 6997-7006 10.2147 /ijn.S145951.

[53] R. Bansal, B. Nagorniewicz, J. Prakash, Clinical Advancements in the Targeted Therapies against Liver Fibrosis, Mediators Inflamm 2016 (2016) $762972410.1155 / 2016 / 7629724$.

[54] L. Appold, Y. Shi, S. Rütten, A. Kühne, A. Pich, F. Kiessling, T. Lammers, Physicochemical Characterization of the Shell Composition of PBCA-Based Polymeric Microbubbles, Macromolecular Bioscience 17(10) (2017) 1700002 10.1002/mabi.201700002.

[55] K.T. Warzecha, M. Bartneck, D. Mockel, L. Appold, C. Ergen, W. Al Rawashdeh, F. Gremse, P.M. Niemietz, W. Jahnen-Dechent, C. Trautwein, F. Kiessling, T. Lammers, F. Tacke, Targeting and Modulation of Liver Myeloid Immune Cells by Hard-Shell Microbubbles, Adv Biosyst 2(5) (2018) 10.1002/adbi.201800002.

[56] F. Gremse, B. Theek, S. Kunjachan, W. Lederle, A. Pardo, S. Barth, T. Lammers, U. Naumann, F. Kiessling, Absorption reconstruction improves biodistribution assessment of fluorescent nanoprobes using hybrid fluorescencemediated tomography, Theranostics 4(10) (2014) 960-71 10.7150/thno.9293. [57] F. Gremse, M. Stark, J. Ehling, J.R. Menzel, T. Lammers, F. Kiessling, Imalytics Preclinical: Interactive Analysis of Biomedical Volume Data, Theranostics 6(3) (2016) 328-41 10.7150/thno.13624.

[58] C. Hage, F. Gremse, C.M. Griessinger, A. Maurer, S.H.L. Hoffmann, F. Osl, B.J. Pichler, F. Kiessling, W. Scheuer, T. Poschinger, Comparison of the Accuracy of FMT/CT and PET/MRI for the Assessment of Antibody Biodistribution in Squamous Cell Carcinoma Xenografts, Journal of nuclear medicine : official publication, Society of Nuclear Medicine 59(1) (2018) 44-50 10.2967/jnumed.117.197178. 